\title{
Fifty years of hypersonics: where we've been, where we're going
}

\author{
John J. Bertin, Russell M. Cummings \\ Department of Aeronautics, United States Air Force Academy, USAF Academy, CO 80840, USA
}

\begin{abstract}
Hypersonic flight has been with us since 22 September 1963, when Robert M. White flew the North American X-15 at $4520 \mathrm{mph}$ at an altitude of 354, $200 \mathrm{ft}$ - a Mach number of 6.7! This remarkable achievement was accomplished over six decades due to intensive research and development by a large number of scientists and engineers. In spite of that momentous achievement, designers have found the hypersonic environment to be harsh and non-forgiving. New programs since the 1960s have often uncovered the unknown unknowns, usually the hard way - early flights of new systems have often revealed problems of which the designers were unaware. Such problems include: the ineffectiveness of the body flap for the Space Shuttle Orbiter, the viscous/inviscid interactions produced by the umbilical fairings that damaged the conical section tile protection system of the Gemini Capsule, and the shock/shock interaction that damaged the X-15A-2 when it carried the hypersonic ramjet experiment. In order to continue to make advances in hypersonic flight a sustained and visionary effort is essential to generate required knowledge and technology. In order to better prepare for future developments in hypersonic flight, this article reviews the advances made within the past 50 years and then looks into the future, not just for new technological developments, but for new ways of thinking about the unknown challenges that lie ahead.
\end{abstract}

\section{Contents}

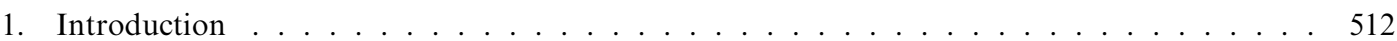

2. Aerothermodynamics . . . . . . . . . . . . . . . . . . . . . . 514

2.1. Stagnation region flow field . . . . . . . . . . . . . . . . 517

2.2. High-speed boundary-layer transition . . . . . . . . . . . . . . . . . . . . 519

2.3. Viscous interactions . . . . . . . . . . . . . . . . . . 522

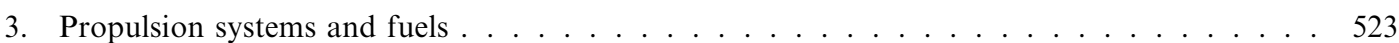

3.1. The access-to-space mission . . . . . . . . . . . . . . . . . . . . 524

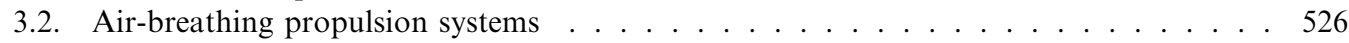

3.3. Fuels . . . . . . . . . . . . . . . . . . . . . . . 527

3.4. Ascent flight . . . . . . . . . . . . . . . . . . . . . 527

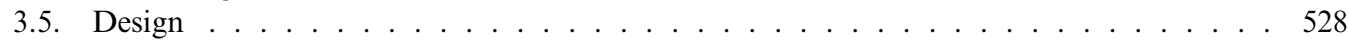




\begin{tabular}{|c|c|c|c|}
\hline \multicolumn{2}{|c|}{ Nomenclature } & $\operatorname{Re}$ & Reynolds number, $\equiv(\rho U l) / \mu$ \\
\hline$a$ & speed of sound & $T$ & temperature \\
\hline$A$ & reference area & $T$ & thrust \\
\hline$C$ & proportionality factor in Eq. (4) & $U$ & magnitude of the velocity \\
\hline$C_{\mathrm{D}}$ & drag coefficient & $\Delta V$ & theoretical velocity potential \\
\hline$C_{p}$ & pressure coefficient, $\equiv\left(p-p_{\infty}\right) / q_{\infty}$ & $W$ & weight \\
\hline$f_{\text {inert }}$ & inert mass fraction, Eq. (8) & $B$ & ballistic coefficient, Eq. (3) \\
\hline$I_{\mathrm{sp}}$ & specific impulse & $\gamma$ & ratio of specific heats \\
\hline$k$ & roughness height & $\mu$ & viscosity \\
\hline$l$ & characteristics body length & $\theta$ & surface inclination angle \\
\hline $\begin{array}{l}M \\
m_{\text {inert }}\end{array}$ & $\begin{array}{l}\text { Mach number, } \equiv U / a \\
\text { inert mass }\end{array}$ & $\rho$ & density \\
\hline$m_{\text {prop }}$ & propellant mass & \multicolumn{2}{|c|}{ Subscripts } \\
\hline$q$ & $\begin{array}{l}\text { dynamic pressure, } \equiv \rho U^{2} / 2=\gamma p M^{2} / 2 \text {, also } \\
\text { heat transfer rate }\end{array}$ & $k$ & $\begin{array}{l}\text { conditions evaluated a distance } k \text { from the } \\
\text { wall in a laminar boundary layer }\end{array}$ \\
\hline$q_{r, t}$ & $\begin{array}{l}\text { radiative heating rate to the stagnation point } \\
\text { of a reference sphere }\end{array}$ & $t 2$ & $\begin{array}{l}\text { conditions at the stagnation point down- } \\
\text { stream of a normal shock wave }\end{array}$ \\
\hline$q_{r, \text { ref }}$ & convective heating rate to the stagnation & $\infty$ & free-stream conditions \\
\hline$R$ & & & level \\
\hline
\end{tabular}

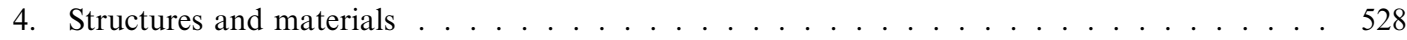

4.1. Propellant tanks . . . . . . . . . . . . . . . . . . . . . . . 529

4.2. Thermal protection systems (TPS) . . . . . . . . . . . . . . . . . 530

4.3. Load-carrying structures . . . . . . . . . . . . . . . . . . 532

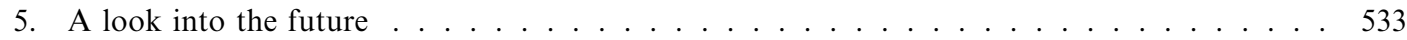

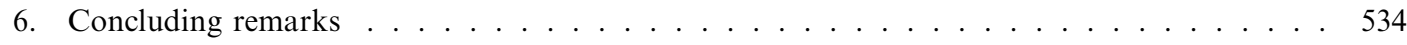

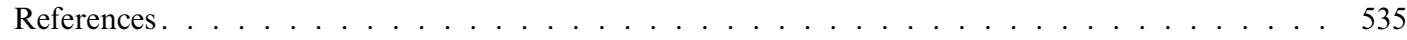

\section{Introduction}

Addressing his graduate class in gas dynamics at Rice University in 1962, H. K. Beckmann said [1], "Mach number is like aborigine counting: one, two, three, four, many. Once you reach many, the flow is hypersonic." Although this oversimplifies the problem, the flow fields around blunt bodies begin to exhibit many of the characteristics of hypersonics when the Mach number is five, or greater. Using the definition for the Mach number, the basic assumption for all hypersonic flow theories is

$M_{\infty} \equiv \frac{U_{\infty}}{a_{\infty}} \gg 1$.

Thus, for hypersonic flows, the internal thermodynamic energy of the free-stream fluid particles is small when compared with the kinetic energy of the free stream.

The term "hypersonic" to describe a flow where the flight velocity was much greater than the ambient speed of sound was first used in a paper by Tsien in 1946 [2]. In 1952, Dr. Walter Dornberger, who had played a key role in the World War II rocket programs at Peenemuende, provided his new boss Larry Bell, President of Bell Aircraft Corp. with data on every aspect of the A-4b and the A-9/A-10 programs [3]: tech reports, blueprints, engineering design data, test reports, photographs, and motion picture film. The Cold War that was developing between the United States and the Soviet Union focused considerable resources into the development of longrange, high-speed missile systems capable of delivering weapons of mass destruction over intercontinental distances. As the velocity, range, and payload capabilities of these missile systems grew, they became the launch platforms for access-to-space programs. Starting with the launch of the Sputnik on 4 October 1957, the first missions were to place small satellites into earth orbit.

Then, in the early 1960s, they were used as the launch vehicles for the initial flights that propelled astronauts/ cosmonauts into space. Astronauts were rocketed into 
sub-orbital and orbital trajectories atop missile systems that had been designed for military applications. There were two, divergent design philosophies for the vehicles that would return the astronauts/cosmonauts safely to Earth. One camp favored the relatively simple, low L/D capsules. A second group favored higher $\mathrm{L} / \mathrm{D}$ vehicles, which were more complex and expensive to design and to build, but which offered more mission flexibility. The capsule community held sway from the late 1950s through the 1970s. In April 1961, Yuri Gagarin completed one orbit and returned safely to Earth in the capsule, Vostok I. American astronauts were soon returning from space in unpowered Mercury and Gemini capsules. But the rockets, which had been developed for the military missions, were expensive to operate and often experienced long delays to the launch date in order to insure that the mission could be conducted safely. The low lift-to-drag ratios of the reentry capsules offered little cross-range capability and, therefore, little flexibility in the mission profile.

To overcome the restrictions placed on the mission flexibility by returning from orbit in low lift-to-drag ratio capsules, the US Air Force initiated the Dyna-Soar (X-20) program in 1957 as a continuation of its research on manned, high-speed flight [4]. The Dyna-Soar program grew out of concepts first proposed in the 1930s by Eugen Saenger, a German scientist. The design and development program for the Dyna-Soar program continued from 1957 to 1963 , with the final configuration being a high lift-to-drag ratio (the predicted maximum $\mathrm{L} / \mathrm{D}$ during entry was 1.8 ), winged glider that was stable and controllable over a large angle-ofattack range. Selecting a high $\mathrm{L} / \mathrm{D}$ with a large bank angle would produce a long, turning entry and very high cross range. As noted in Ref. [4], "Several known technical problems or expected delays were on the horizon at program termination in late 1963. None of these were considered major hurdles by the X-20 team members at the time, but their true impact will never be known."

Many of the early aerospaceplane concepts incorporated an advanced airbreathing propulsion system as one element of its propulsion system. Thus, during the mid-1960s, the National Aeronautics and Space Administration (NASA) attempted to develop a flight-worthy supersonic combustion ramjet (Scramjet). Hallion [5] wrote: "This project, the hypersonic ramjet experiment (HRE), cost $\$ 50$ million, and generated only one noteworthy accomplishment: 'the illumination of critical unknowns', as author John V. Becker writes. It is a graphic example of what happens when an immature technology is pushed too fast too soon, in the absence of comprehensive thought and planning and with zeal replacing insight." With the cancellation of the HRE project, vehicles were accelerated to hypersonic speeds by rocket propulsion systems for generations to come.
The Space Shuttle, which was designed and developed in the 1970s and in the early 1980s, was intended to make access to space a routine and inexpensive activity. However, in the 20 years since the first flight of the Space Shuttle, access-to-space remains an expensive and relatively inflexible activity.

If one were to fast forward 50 years from the programs described in the previous paragraphs to today, the mission goals of today are similar to those faced by the designers of the early 1950s. The authors of the present paper propose that there are, at least, three mission goals that require vehicles capable of hypersonic speeds. They are to:

1. Deliver decisive blows at the outset of hostilities, with the goal of destroying the adversary's ability to fight a protracted war.

2. Deliver cost-effective weapons to defeat time-critical targets and to establish in-theater dominance, if a protracted war cannot be avoided.

3. Maintain flexible, readily accomplished access to space.

All three missions are vital to the military forces. Access to space is important not only to the military community, but it is also important to the Federal Government's non-military space program and to the business community, i.e., commercial interests.

If hypersonic vehicles that can successfully accomplish these three broad mission areas are to be designed and built, advances need to be made in all four Knowledge Management Domains of the notional presentation of Knowledge Management Space that has been developed by Matsch and McMasters [6]. See Fig. 1.

To reduce the cost or to improve the reliability of accessing space, programs must seek to apply advancements in technology and/or in processes. Incremental changes can produce evolutionary progress. Thus, technology relating to non-intrusive diagnostics whose fundamental principles and method of application are known can be applied to slightly different applications to improve operability and reduce recurring costs. This is indicated by the upper right-hand quadrant of the notional presentation of Knowledge Management Space (Fig. 1) that was developed by Matsch and McMasters [6]. Such evolutionary progress can be accomplished readily by the companies that design and produce the hypersonic systems. The upper left-hand quadrant of Fig. 1 addresses capabilities of which we are aware, but do not know how to design or build the desired system to deliver these capabilities. Once technologies that represent a significant advance to a system's capability have been identified, such as Scramjet propulsion systems, programs of targeted research can be planned and executed. Targeted-research programs address technologies of which we are aware, but which are 


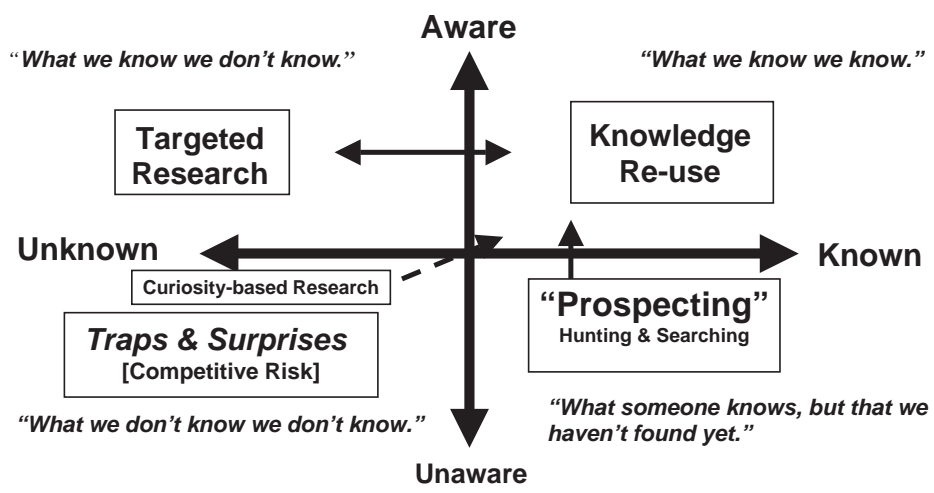

Fig. 1. Opportunities in a Balanced Exploration of the Knowledge Management Domain Ref. [6].

beyond the present state-of-the-art. Targeted-research programs most likely will require considerable time and/or very large allocations of personnel resources, computer hardware and software, and test facilities. Therefore, the authors believe that ambitious, targetedresearch programs are best accomplished by federal labs, i.e., the US Air Force Research Laboratories, the NASA Centers, and the D.O.E. Laboratories.

In the mid 1990s, a panel of the U. S. A. F. Scientific Advisory Board under the direction of chairman Richard Bradley identified four key hypersonic concepts including missiles, maneuvering reentry vehicles, a rapid response/global-reach aircraft system, and a space launch/support system [7]. The technological developments that are required to support these four concepts are summarized in Table 1 .

In the text that follows the authors will discuss the phenomena associated with three broad disciplines:

\section{Aerothermodynamics}

2. Propulsion systems and fuels

3. Structures and materials

For each discipline, the presentation of material will review the significant advances that have been made in hypersonic-related technology (including examples in those areas where the design teams sought to generate information about known unknowns and other instances where the design team encountered unknown unknowns). An important concept [1] is that there are both known unknowns and unknown unknowns. Certain critical unknowns are identified during the design process, e.g., the uncertain effect of misaligned tiles on boundary-layer transition for the Shuttle Orbiter. The known unknowns are then made the subject of targeted-research programs. Although tests have been conducted and flow fields have been computed, questions may remain about the validity of the models when applied to flight conditions. The designers compensate for the uncertainties in the known unknowns (or pre-flight concerns) by restricting the flight envelope, by adding to the thermal protection system, etc. Maneuvers are designed and data are obtained during the early flights to answer questions related to the known unknowns. In reality, of equal or of greater concern to the designer are the unknown unknowns, i.e., those phenomena that might produce catastrophic failures but were not identified during the design process. Two such unknown unknowns are the shock/shock interaction phenomena that damaged the ventral fin on the $\mathrm{X}-15$ and the fact that the pitching moment during the re-entry of the Shuttle Orbiter was outside the expected variations, causing body-flap trim problems. Unknown unknowns are usually discovered during flight tests and could present drastic consequences to the survival of the vehicle or of the crew and lead to unacceptable increases in the costs to develop the vehicle. Having analytical/numerical and experimental capabilities that can adequately model hypersonic flow fields is essential to the cost effective development of hypersonic vehicles.

\section{Aerothermodynamics}

The thermochemistry of high-temperature reacting gases that is associated with hypersonic flight is difficult to match in ground-test facilities. With exceptions for extremely brief test times, the high total-enthalpies associated with hypervelocity flight cannot be simulated in ground-based test facilities without damaging the facility and/or the model. Therefore, for wind-tunnel applications, the test gas is expanded so that the static temperature in the test section is just above the liquefaction temperature. As a result, the free-stream speed of sound is very low. Assuming that the test gas in the free-stream behaves as a perfect gas:

$a_{\infty}=\sqrt{\gamma R T_{\infty}}$.

Since the gas expands from nominal total temperatures in the stagnation chamber of the wind tunnel to very low 
Table 1

Technologies and associated Mach number range

\begin{tabular}{|c|c|c|c|c|}
\hline & Missiles (accelerators) & $\begin{array}{l}\text { Maneuvering reentry } \\
\text { vehicles (accelerators) }\end{array}$ & $\begin{array}{l}\text { Rapid response/global } \\
\text { reach aircraft systems } \\
\text { (cruisers) }\end{array}$ & $\begin{array}{l}\text { Space launch/support } \\
\text { system (accelerators) }\end{array}$ \\
\hline Mach number & $1-6$ & $0-20$ & $0-18$ & $0-25$ \\
\hline \multicolumn{5}{|c|}{ Enabling technologies } \\
\hline \multirow[t]{5}{*}{ Aerodynamics } & High lift/drag ratio & High lift/drag & Low drag & Low drag \\
\hline & Low drag & Minimal aero heating & $\begin{array}{l}\text { Airframe-prop } \\
\text { integration }\end{array}$ & $\begin{array}{l}\text { Airframe-prop } \\
\text { integration }\end{array}$ \\
\hline & $\begin{array}{l}\text { Airframe propulsion } \\
\text { integration }\end{array}$ & Flow modification & High L/D & Low aero heating \\
\hline & Controls & & Control effectiveness & Control effectiveness \\
\hline & & & Flow modification & Flow modification \\
\hline \multirow[t]{4}{*}{ Propulsion } & Rocket & Rocket & Rocket & Rocket \\
\hline & $\begin{array}{l}\text { Dual-mode ramjet/ } \\
\text { scramjet }\end{array}$ & & Combined cycle & Combined cycle \\
\hline & & & $\begin{array}{l}\text { Dual-mode ramjet/ } \\
\text { scramjet }\end{array}$ & $\begin{array}{l}\text { Dual-mode ramjet/ } \\
\text { scramjet }\end{array}$ \\
\hline & & & External burning & External burning \\
\hline \multirow[t]{3}{*}{ Fuels } & Hydrocarbon & & Hydrocarbon & Hydrocarbon \\
\hline & Endothermic HC & & Endothermic HC & Endothermic HC \\
\hline & & & Hydrogen & Hydrogen \\
\hline \multirow[t]{3}{*}{ Structures } & Heat sink & Thermal protection & Fuel cooled & Fuel cooled \\
\hline & Ablatives & Radiation cooled & Radiation cooled & Radiation cooled \\
\hline & & & Long life structure & $\begin{array}{l}\text { Low structural weigh } \\
\text { fraction }\end{array}$ \\
\hline
\end{tabular}

static temperatures in the test section, hypersonic Mach numbers are achieved through relatively low speeds-ofsound. Thus, for tests conducted in a wind tunnel, $M_{\infty}$ is very large because the free-stream speed of sound (which is proportional to the square root of the freestream temperature) becomes very small while the freestream velocity is held fixed. As a result, the fluid temperatures in the flow fields around the models tested in such wind tunnels remain below the levels that would damage the wind tunnel or the model.

For flight applications, $M_{\infty}$ is very large because the free-stream velocity is very high while the free-stream thermodynamic state remains fixed. The flow slows down as it crosses the shock wave that envelopes the vehicle, producing extremely high temperatures in the shock layer. The kinetic energy of the air particles in the flow field associated with a vehicle in hypervelocity flight is converted into increasing the temperature of the air and into endothermic reactions, such as dissociation and ionization of the air near the vehicle's surface. The mechanisms for this conversion include adiabatic compression and viscous energy dissipation. Heat is transferred to the surface from the high-temperature air in the shock layer. The rate at which heat is transferred to the surface depends upon many factors, including the free-stream conditions, the configuration of the vehicle and its orientation to the flow, the difference between the temperature of the air in the shock layer and the temperature of the vehicle's surface, and the surface catalycity. In order to generate solutions for the flow field, the designer must simultaneously solve the continuity equation, the momentum equation, and the energy equation. Thus, those responsible for the design of a hypersonic vehicle must determine the aerodynamic heating environment as well as the aerodynamic forces and moments. Hence, we use the term "Aerothermodynamics" as the title for this section.

Allen and Eggers [8] noted that, if an object is of relatively light weight, it will quickly be decelerated to relatively low speeds, even if acted upon by low drag forces, i.e., if it is a low-beta configuration. Beta is known as the ballistic coefficient (or the weight-to-drag ratio) and is given by the equation:

$\beta=W /\left(C_{\mathrm{D}} A\right)$.

For such objects (or vehicles), the convective heating is minimized by employing shapes with high-pressure drag. Such shapes maximize the amount of heat delivered to the atmosphere and minimize the heat delivered to the body in the deceleration process. Single Shuttle tiles 
reentering the atmosphere after the Columbia accident had values in the range $2.4-35 \mathrm{~kg} / \mathrm{m}^{2}$.

On the other hand, if the missile is so heavy or has such a relatively low drag that it is only slightly retarded by the aerodynamic drag, irrespective of the magnitude of the drag force, i.e., a high-beta configuration, then the convective heating is minimized by minimizing the total shear force acting on the vehicle. Allen and Eggers [8] define this as "the small cone angle case." Indeed, the small half-angle cones typical of ballistic missiles are examples of high-beta configurations. Values of beta that are typical of ballistic missiles are in excess of $500 \mathrm{~kg} / \mathrm{m}^{2}$.

Because of their very high-drag characteristics, the early manned entry vehicles (e.g., the Mercury, the Gemini, and the Apollo Command Module) and winged vehicles that enter at high angles-of-attack (e.g., the Space Shuttle Orbiter and the Hermes) had mid-range values of beta.

The approximate velocity/altitude parameters for several different programs are presented in Fig. 2. These parameters are presented in Fig. 2 for the trajectory of an aeroassisted space transfer vehicle (ASTV), for two re-entry trajectories for the Apollo Command Module (an overshoot trajectory and a 20-g limit trajectory), for the best-estimated trajectory for the re-entry of the STS-2 (Shuttle Orbiter), for the flight of a single-stageto-orbit (SSTO) vehicle powered by an air-breathing engine, and for the trajectory for a slender (relatively low-drag) re-entry vehicle. Included in Fig. 2 are lines of constant free-stream Mach number and of constant freestream Reynolds unit number. The aerothermodynamic phenomena, which are important to the design of four major classes of hypersonic space-transport vehicles, as presented by Hirschel [9], are reproduced in Fig. 3. The four classes of vehicles for which nominal trajectories are presented include:

1. Winged re-entry vehicles (RV), such as the Space Shuttle Orbiter, the Buran, and Hermes,

2. Hypersonic cruise vehicles (CV), such as the first stage of the Saenger space transportation system,

3. Ascent and re-entry vehicles (ARV), such as the upper stage Horus of the Saenger system, and

4. Aeroassisted orbit transfer vehicles (AOTV), also known as aeroassisted space transfer vehicles (ASTV).

For applications, such as the return of manned capsules from extra-terrestrial missions, e.g., the Apollo Command Module, the vehicle re-enters the earth's atmosphere at super-orbital speeds at relatively high altitudes, i.e., in the upper right-hand corner of Figs. 2 and 3. The initial flight-path angle is relatively small. Since the vehicle is relatively blunt and/or flies at relatively high angles-of-attack, the hypersonic deceleration occurs at very high altitudes. Since the vehicle reenters the earth's atmosphere at Mach numbers in excess of thirty, the temperatures in the shock layer exceed $6600 \mathrm{~K}$ and the vehicle's surface is exposed to radiative as well as to convective heating. The designers of the Apollo Command Module had to account for strong real-gas effects (including non-equilibrium thermochemistry, ionization, and radiation from the gas cap to the vehicle's surface and from the vehicle's surface back into

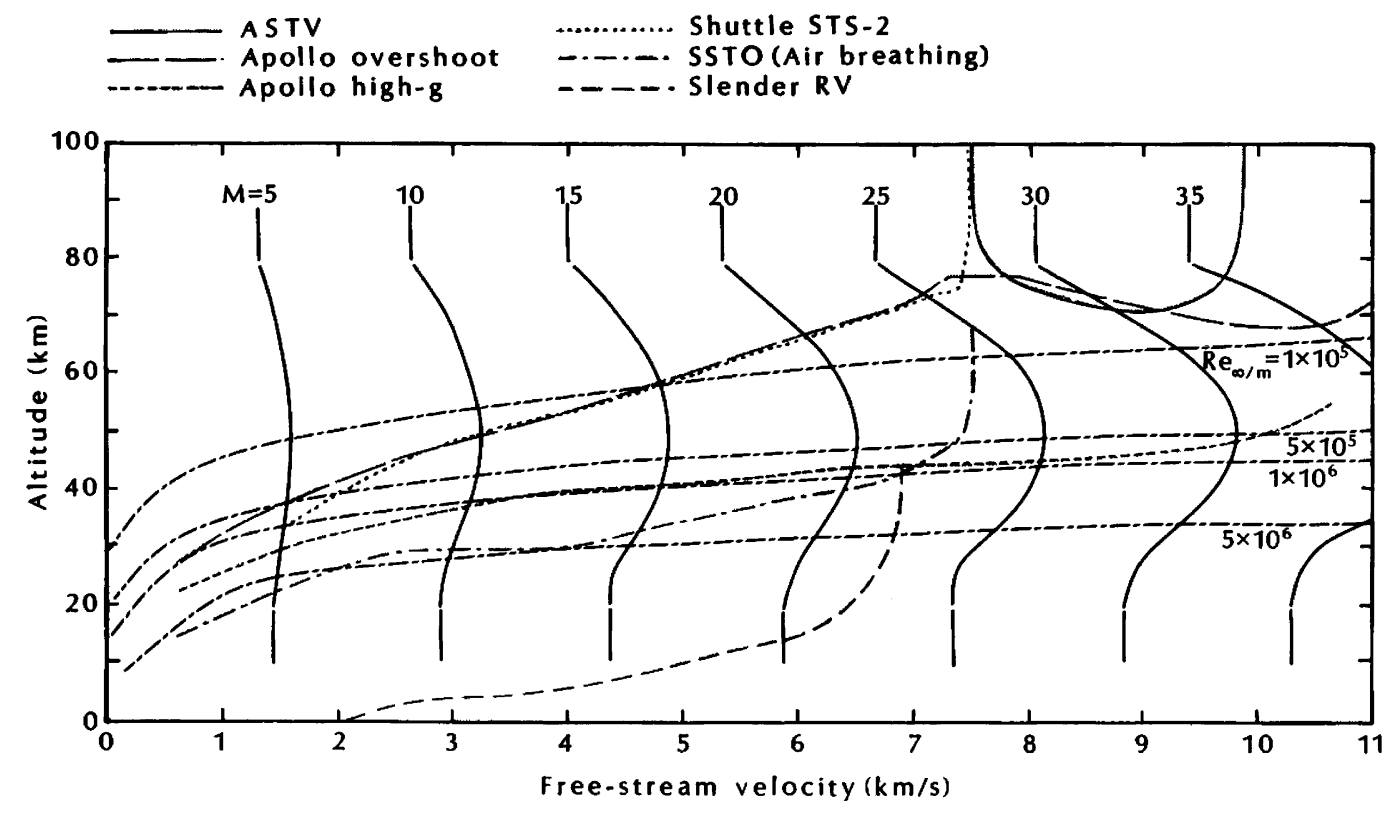

Fig. 2. Lines of Constant Mach Number and of Constant Unit Reynolds Number Ref. [1]. 


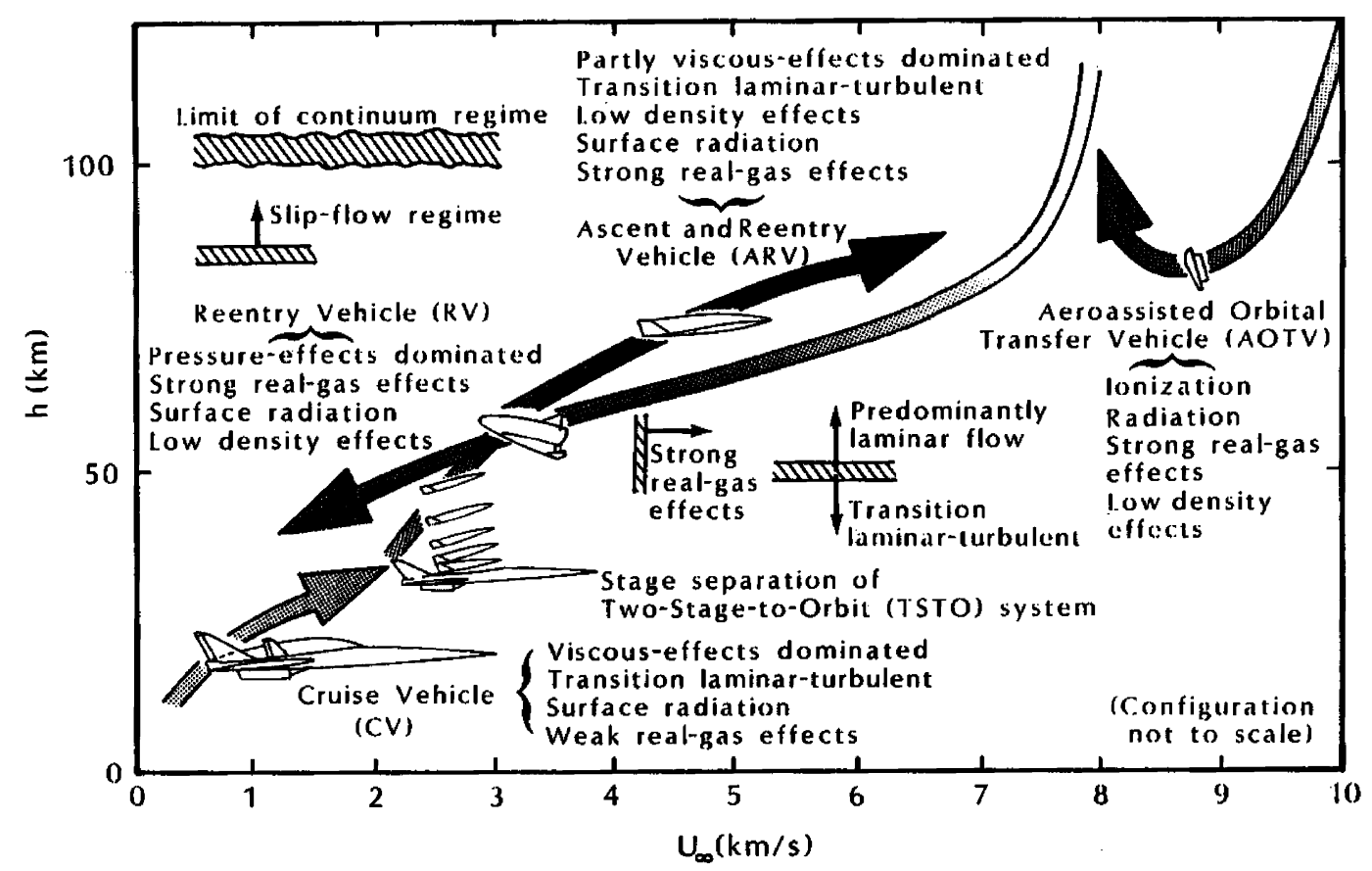

Fig. 3. Four Major Classes of Hypersonic Space-Transport Vehicles, and Major Aerothermodynamic Effects Ref. [9].

the shock layer) and low-density effects [including lowReynolds-number viscous/inviscid interactions and (possibly) noncontinuum flow models]. These design challenges will be discussed further under the subheading: "Stagnation Region Flow Field".

A hypersonic vehicle with an air-breathing propulsion system must operate at relatively low altitudes in order to maintain the relatively high dynamic pressures required for maximum engine performance, i.e., capture sufficient air to enable the air-breather to operate efficiently. Thus, a hypersonic vehicle, which is powered by an air-breathing propulsion system, often flies for extended periods of time at altitudes from 30 to $50 \mathrm{~km}$, as indicated in Fig. 3. It is, therefore, subjected to high convective heating rates and may require active cooling as part of the thermal protection system (TPS). However, the problem is further complicated by the fact that the Reynolds numbers for these flight conditions are in the range where boundary-layer transition may occur. Since there is considerable uncertainty in the boundary-layer transition methodology and since the convective heating from a turbulent boundary layer is much greater than that from a laminar boundary layer, this transition uncertainty presents critical challenges to the designer. These design challenges will be discussed further under the sub-heading: "High-Speed BoundaryLayer Transition".

Starting with the Dyna Soar configuration in 1957 [7], designers recognized the advantages of the high lift-todrag ratios provided by winged re-entry vehicles.
However, the designers of vehicles that are to fly at hypersonic speeds have long recognized that the locally severe heating rates produced by viscous/inviscid interactions and by shock/shock interactions can cause catastrophic failures. One of the first in-flight confirmations of the severity of shock-impingement heating occurred in October 1967, when the X-15A-2 suffered severe damage to its ventral fin (pylon) during a highaltitude flight at Mach 6.7. The ventral fin (or pylon) supported a dummy model of the HRE for the last three flights of the X-15 flight-test program. On 5 May 1967, the X-15A-2 with no ablative coating was flown to a maximum velocity of $1.448 \mathrm{~km} / \mathrm{s}$. The main purpose of this flight was to evaluate the handling qualities of the aircraft with the dummy ramjet engine installed [10]. Two flights were then made with an ablative heat shield protecting the X-15A-2 and with the dummy ramjet attached. In October 1967, on the second flight, the aircraft achieved $2.021 \mathrm{~km} / \mathrm{s}$. Although the ablative heat shield protected the aircraft structure, a shock/shock interaction produced considerable damage to the dummy ramjet and to the ramjet pylon. Gaping holes were burned in the pylon and four probes were lost. These design challenges will be discussed further under the subheading: "Viscous Interactions".

\subsection{Stagnation region flow field}

The attention given to developing the technology base for missiles and for manned spaceflight in the 1950s 
attracted many talented researchers to focus on investigations of hypersonic flow fields. The local convective heat-transfer rates and the local surface pressures are usually the greatest at the stagnation point, which is downstream of the normal portion of the bow-shock wave. Furthermore, these two parameters are often used as the denominator in non-dimensional correlations of the pressure distributions and of the convective heattransfer distributions. Thus, considerable attention was given to defining the flow field in the stagnation region. In 1955, Lees [11] introduced the concept of a modified Newtonian flow to model the surface pressure distribution for a configuration in a hypersonic flow [1]:

$C_{p}=C_{p, t 2} \sin ^{2} \theta$.

Once we were able to approximate the surface pressure distribution, the next step was to solve the boundary-layer equations in order to estimate the convective heating to the stagnation point on the vehicle. The correlations developed by Lees [12] and by Fay and Riddell [13] were among the most widely used by the designers of that time to generate estimates of the stagnation-point convective heating rate. Local flow parameters (at the edge of the boundary layer and at the wall) are needed to calculate the stagnation-point heattransfer rate, if one uses the equations derived by Lees [12] or by Fay and Riddell [13]. However, Fay and Riddell noted that: "Despite the importance of the process of dissociation and recombination in determining the thermodynamic state of the air throughout the flow field, their effect on heat transfer is secondary." Thus, as shown in Bertin [1], an approximate value for the stagnation-point heat-transfer rate can be calculated using the nose radius, the free-stream density, and the free-stream velocity:

$q_{t, \mathrm{ref}}=C \rho_{\infty}^{0.5} U_{\infty}^{3} / R_{\mathrm{N}}^{0.5}$.

The value of $C$, the constant in Eq. (5), depends on the units used for the other parameters. The nose radius accounts for the fact that the stagnation-point heattransfer rate depends on the stagnation-region velocity gradient at the edge of the boundary layer: the smaller the nose radius, the higher the stagnation-point heattransfer rate.

The relation between the nose radius and the velocity gradient for the flow at the edge of the boundary layer near the stagnation point depends upon many factors. If the spherical portion of the nose is truncated before the local flow in the shock layer reaches sonic speeds, the sonic line is located at the "corner" formed by the truncation. This would be inside the location of the sonic line for the situation, where the spherical portion of the nose cap continued into the locally supersonic flow. Changes to the inviscid flow propagate throughout the subsonic region, increasing the convective heating at the stagnation point. This phenomenon affects the stagnation region flow field for re-entry capsules, e.g., the Mercury Capsule. Ablation of the thermal protection system of a slender missile in a hypersonic stream modifies the shape of the nose, changing the effective nose radius and affecting the boundary-layer transition location.

By the end of the 1950s, the technology base provided a reasonable understanding of the stagnation-region flow fields for relatively simple shapes re-entering the atmosphere at orbital speeds, e.g., approximately $7900 \mathrm{~m} / \mathrm{s}(26,000 \mathrm{ft} / \mathrm{s})$. However, the Apollo program had command modules returning astronauts from the moon that would re-enter the earth's atmosphere at velocities of approximately $11,000 \mathrm{~m} / \mathrm{s}(36,000 \mathrm{ft} / \mathrm{s}$; see Fig. 2). In the early 1960s, researchers from two large organizations worked to develop analytical techniques/ experimental facilities for determining the stagnationpoint heat-transfer rate at superorbital speeds. As shown in Fig. 4, which is taken from Ref. [14], the two groups of researchers developed two dramatically different correlations. Buck et al. [14] noted that there was a controversy at the time regarding the magnitude of the predicted stagnation-point heating rates and the contributing factors that caused the increase in the predicted heating at superorbital velocities. Since the two groups that developed these correlations contained many talented, competent people, the individual researchers and their organizations are not identified. Their identity is not important. What is important is that each team of researchers presented both data and theoretical/numerical results that were consistent with their position. Eventually the correlation giving the lower heat-transfer rates was found to be correct, which translated into

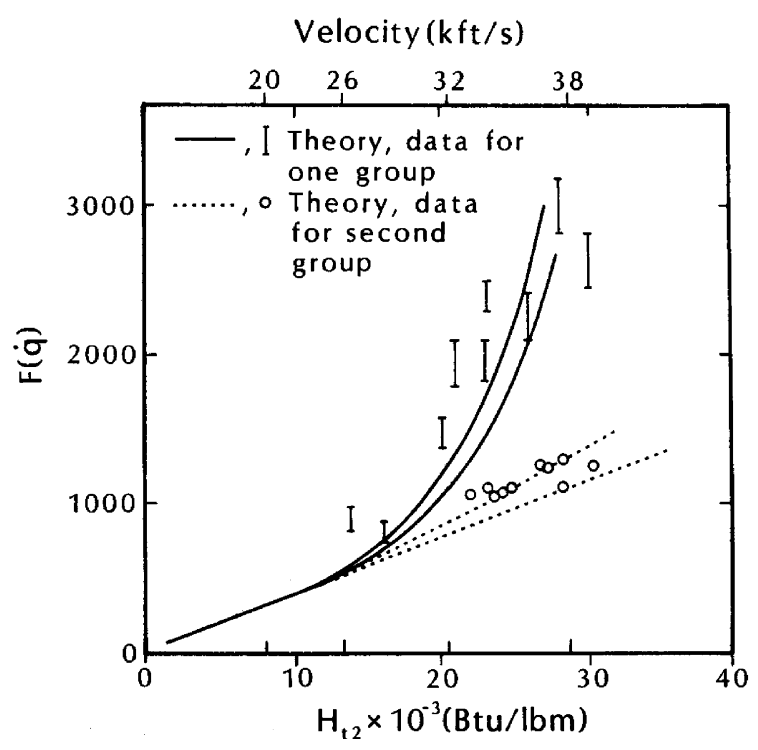

Fig. 4. The Stagnation-point Heat-transfer Correlations at Super-Orbital Speeds Ref. [14]. 
considerable savings in the weight of the thermal protection system for the Apollo Command Module.

Measurements obtained in ground-based test facilities reflect the limitations associated with those flow simulations. Furthermore, no matter how powerful the computer hardware, computed flow fields reflect the limitations associated with the flow models and the numerical algorithms employed. Note that whether referring to data from ground-based test facilities or to computed flow fields, the authors have used the term: "modeling". The limitations both of ground-based tests and of computed flow fields will be a recurring theme throughout this paper. Thus, the reader should appreciate the need for comparing experimental measurements with computed results (and vice versa) to calibrate and to validate these tools.

The designers of vehicles, which are intended to fly in the earth's atmosphere at superorbital speeds, must address issues related to radiation to and from the gases in the shock layer. The analysis developed by Martin [15] indicates that the gas-to-surface radiation for a reentry vehicle may be estimated as

$q_{r, t}=C R_{\mathrm{N}}\left(\frac{\rho}{\rho_{\mathrm{SL}}}\right)^{1.6}\left(\frac{U_{\infty}}{10000}\right)^{8.5} \mathrm{~W} / \mathrm{cm}^{2}$.

Again, note that the value of the constant $C$ depends on the units of the other parameters.

Martin noted, "that up to satellite velocity one may treat surface heat transfer as arising exclusively in the aerodynamic boundary layer to the accuracy of the engineering approximations describing the heat transfer." According to Martin, radiation and convective heating, i.e., that from the aerodynamic boundary layer, become comparable for a one-foot radius sphere at a free-stream velocity of $12,200 \mathrm{~m} / \mathrm{s}(40,000 \mathrm{ft} / \mathrm{s})$.

Sutton [16] noted that radiative heat-transfer technology is important to ASTVs and to Martian return vehicles, because they enter the earth's atmosphere at relatively high velocities and have a large frontal area in order generate the desired large drag forces. Assuming that the air in the gas cap was in chemical equilibrium, Sutton generated radiatively coupled solutions for the inviscid, stagnation-region flow fields for a variety of environments. A flight-test program was conducted to determine the re-entry heating environment for a blunt, capsule shape flying at superorbital speeds. Measurements were made of the heating-rate histories and the total heating rate for Fire II, which was an "Apollo-like" configuration with a layered heat shield. The initial entry velocity for Fire II was in excess of $11,000 \mathrm{~m} / \mathrm{s}(36,000 \mathrm{ft} /)$. Heat Shields 1 and 2 were ejected sequentially during re-entry to expose a clean surface for the next data period. At peak heating, the calculations of Sutton indicated that 35 percent of the total heating was due to absorbed radiation.
As reported by Lee and Goodrich [17] measurements from the stagnation region during the re-entry of Apollo Spacecraft 017 indicated a peak radiative heating rate of $115 \mathrm{~W} / \mathrm{cm}^{2}\left(100 \mathrm{Btu} / \mathrm{ft}^{2} \mathrm{~s}\right)$. This is roughly one-fourth of the maximum heating rate.

Because of the very high velocities associated with interplanetary flight, radiative heating becomes a major factor in defining the aerothermodynamic environment for the vehicles designed for missions beyond the earth's orbit. To develop predictive techniques for estimating radiative heating, one must have models for nonequilibrium thermochemistry, for radiative energy transfer mechanisms, and for absorption and retransmission of radiative energy within the shock layer. The development of predictive techniques for estimating radiative heating requires considerable advancement in the fundamental physics and chemistry of the governing phenomena. Such problems fall under the description that "we don't know what we don't know". This typifies the curiosity-based research described in the lower lefthand quadrant of Fig. 1. Furthermore, the missions for which these applications would be critical are in the distant future. The authors believe that the long-term commitment to curiosity-based research that has considerable risk relative to the payoff is best assigned to the federal labs and to the universities.

\subsection{High-speed boundary-layer transition}

The effective prediction of boundary layer transition has long challenged engineers, even for low-speed, incompressible-flow applications. As the flow reaches supersonic, and then hypersonic, speeds, transition becomes even more difficult to understand and to predict. Numerous flow field parameters affect transition in hypersonic flow, including the local Mach number, surface cooling, the unit Reynolds number, nose bluntness (including the effect of entropy swallowing), cross-flow or three-dimensional effects, surface roughness, protuberances, and mass injection. In addition, if the hypersonic flow is dissociated and/or ionized, gas chemistry may also influence transition. A summary of the impact of each of these factors on transition may be found in Ref. [1].

In order to develop correlations that can be used to predict the onset of boundary-layer transition, a variety of experiments have been conducted at supersonic and hypersonic speeds, both with and without heat transfer (see for example Refs. [18-21]). However, despite the large body of literature, no semi-empirical model has been produced that accurately predicts transition at a variety of flight conditions. In addition, attempts have been made to analytically predict transition using linear stability theory, with similarly mediocre results [22,23]. More recent evaluations of the problem in wind tunnels have led researchers to despair that wind tunnel noise 
may invalidate most, if not all, hypersonic transition data that exists [24]. This problem has led to the call for a quiet hypersonic tunnel facility, but difficulties even exist in creating a truly quiet environment for testing [25].

The difficulty in developing criteria for predicting boundary-layer transition is complicated by the fact that the location of the onset of boundary-layer transition is very sensitive to the measurement technique used. The experimentally-determined heat-transfer rates increase above the laminar values at the upstream end of the boundary-layer transition process, i.e., at the onset of the transitional flow. A schlieren photograph of the hypersonic flow field reveals vortices in the boundary layer associated with the various steps in the breakdown (i.e., in the transition) of the boundary layer. However, for a flow as simple as a hypersonic flow over a slender, sharp cone, the boundary-layer transition location determined using the heat-transfer distribution along a conical generator is very different than that determined using a schlieren photograph. This calls into question the methods used to define and to "measure" the "location" at which boundary-layer transition occurs in wind-tunnel tests and in flight tests. The heat-transfer rates approach the fully-turbulent values at the downstream end of the transition process. Owen et al. [26] found that the onset of transition in hypersonic flow can take place at a Reynolds number that is approximately one-third to one-half of the Reynolds number where transition from a laminar boundary layer to a fully turbulent boundary layer has been completed. Thus, transition takes place over a large distance in hypersonic flow. Even if every researcher were to define and measure transition in the same way, the scatter of transition data as a function of Mach number would still be considerable. However, researchers employ a wide range of techniques in a wide variety of test simulations, which results in considerable scatter in transition correlations. This is illustrated in Fig. 5, which was originally presented by Beckwith and Bertram [27] and reproduced as Fig. 7.27 in Ref. [1]. This presentation of data makes it difficult to imagine a single theory or semiempirical relationship that could correlate the data. Making matters worse is the fact that transition rarely occurs along a line-turbulent zones spread and merge in the longitudinal direction, also making the definition of transition more difficult.

Whatever the difficulties in understanding transition in wind tunnels, the difficulties during flight seem even more insurmountable. The situation led Eli Reshotko to state that [28]: "the rational prediction of transition Reynolds numbers in free flight borders on the impossible because of the lack of information on the disturbance environment in flight." While we hope that Reshotko's observation is overly pessimistic, the available evidence certainly paints a bleak picture.

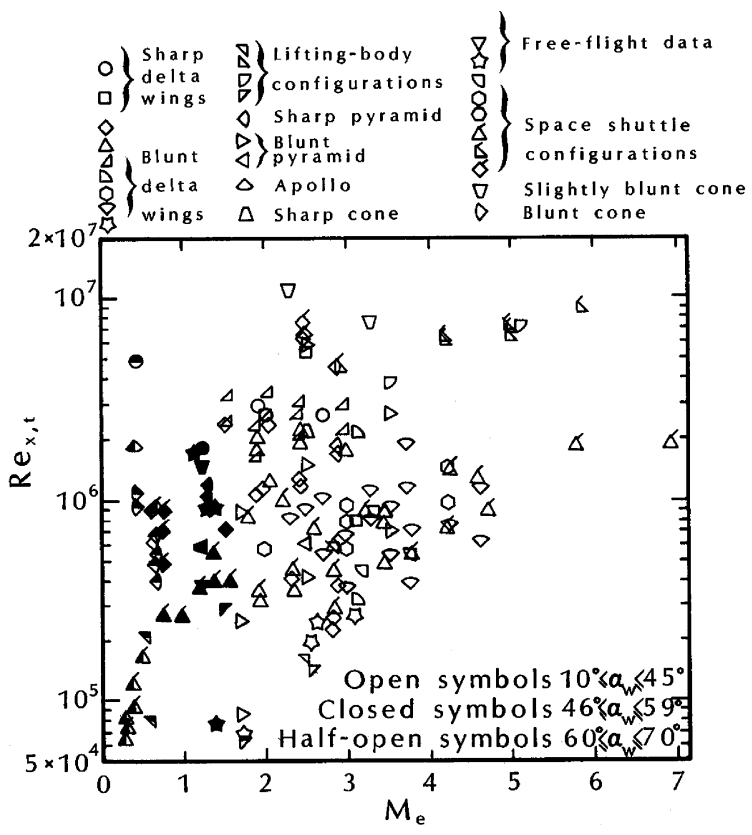

Fig. 5. Transition Reynolds Number as a Function of Local Mach Number Ref. [27].

Schneider's collection of available hypersonic flight test data for transition show results which are equally as scattered as those from wind tunnel tests, with transition taking place at Reynolds numbers that differ by as much as an order of magnitude [29]. Clearly, we are unable to understand or to predict hypersonic boundary-layer transition, whether for a wind-tunnel model or for a flight-test vehicle.

Considering that, for vehicles that are powered by airbreathing propulsion systems, most of the atmospheric hypersonic flight takes place at conditions where the flow will be transitional, the importance of understanding and predicting transition will be critical to the design of future hypersonic vehicles. Finding prediction methods that can give results of suitable engineering accuracy for vehicles that contain TPS, relatively complex geometries, varying surface roughness, and various sharp and blunt surfaces will be challenging. Dennis Bushnell [30] has gone so far as to say that, "historically, man has been singularly unsuccessful in 'predicting' transition on essentially everything flown hypersonically (or even supersonically)." Bushnell goes on to use the $\mathrm{X}-15$ as an example, where wind tunnel data showed that the flow over the vehicle should be mostly laminar, while the flight tests showed that the flow was mostly turbulent. Yet, the importance of knowing the location of transition during hypersonic flight will become increasingly important if advanced vehicles are to be designed that will make hypersonic flight safe, regular, and affordable. 
While most transition models traditionally have been developed based on flat-plate experimental results, future hypersonic aircraft will need more reliable capabilities in predicting transition. The design of future hypersonic aircraft will require designers to be able to account for the implications of the TPS configuration on surface roughness and, therefore, on the state of the boundary layer, including the ability to predict skin friction and heat-transfer rates. Even the same vehicle can exhibit large variations in transition Reynolds number on different flights flying essentially the same trajectory, as has been reported on the Space Shuttle, which uses a labor-intensive tile-installation system on its windward side [31]. Advanced metallic thermal protection systems may have an even more adverse impact on transition prediction. While it may never be possible to take into account all factors that affect transition, designers need the ability to predict nominal conditions with engineering accuracy.

In addition, as future hypersonic vehicles are designed, there will be greater variations in the nose bluntness and wing leading-edge radius, all of which are made possible by improvements in materials and TPS configurations. While early designers were restricted to the use of blunt shapes in order to reduce heating, future designers may use a variety of shapes on their vehicles. This leads to the need for a larger body of knowledge about the impact of nose and leading edge geometries on transition, since much of the early experimental work was done on the blunt shapes that were feasible at the time.

As noted by Reda [32], "Carbonaceous nosetip materials, both graphites and carbon/carbon composites sublime under high altitude laminar-flow conditions, forming a surface microroughness distribution characteristic of each material's composition and fabrication/ processing technique. Surface roughness element heights typically span at least an order of magnitude and can thus only be represented in a statistical sense. Surface microroughness elements, as formed during reentry, create disturbances within the laminar boundary layer. As altitude decreases, Reynolds number increases, and nosetip flowfield conditions capable of amplifying these roughness-induced disturbances are eventually achieved, i.e., transition onset occurs. Boundary-layer transition to turbulence results in more severe heat-transfer rates, increased ablation rates, accelerated shape change, and the formation of a macroroughness pattern downstream of transition (e.g., striations, grooves, and/or scallops) which further augment the turbulent convective heat transfer rates."

Reda [32] continues: "Based on present understanding, transition initially occurs on the nosetip in the vicinity of the sonic line, $\left(S / R_{\mathrm{N}}\right) \approx 0.7$, and progresses forward at a rate dependent on both the material surface roughness and the reentry vehicle trajectory. Under some conditions, this forward progression occurs rapidly, and a rather symmetric/biconic nosetip shape results. However, under conditions where the leading edge of the transition zone remains removed from the stagnation point throughout any appreciable portion of the trajectory, a laminar island forms, followed by an indented/turbulent flow region." In this quote, $S$ is the wetted distance from the stagnation point of the spherical cap and $S / R_{\mathrm{N}}$ is the corresponding angular coordinate.

In a review of roughness-dominated transition correlations for reentry applications, Reda [33] concluded that, whether the surface roughness was associated with an ablating thermal protection system [32] or with nonablating thermal protection systems, such as the heat shields on reusable hypersonic vehicles [34], the transition correlations could be well modeled by the critical roughness Reynolds number concept:

$\operatorname{Re}_{k}=\rho_{k} U_{k} k / \mu_{k}$

The roughness Reynolds number is evaluated based on the conditions in the smooth-wall laminar boundarylayer at a distance from the wall equal to the roughness height.

While some people might be tempted to lay all of these problems at the feet of the experimentalists, a great deal more work needs to be done in creating transition and turbulence models that are used in the numerical solutions and that account for the various factors outlined above. All models for transition and turbulence are semi-empirical in nature, meaning that the numerical models are often only as good as the experiments upon which they have been based. If the experimental results are suspect (such as may be due to tunnel noise or other factors), then the numerical models must be suspect also. This conundrum leads to the need for models that are more fundamental in nature (the equivalent of largeeddy simulation in turbulence models), that do not depend on empirical data, but are based on governing equations and flow physics alone. If the long march to direct numerical simulation of turbulence is any indication, those models will not come easily or at small developmental or computational cost. In addition, transition models for hypersonic flow will need to take into account thermochemistry, which adds another layer of complexity. And once those models have been developed, how will they be validated? If wind tunnel and flight test transition data are 'contaminated' by a variety of factors, we will have great difficulty in knowing when a good transition model has been obtained. The challenges for creating an adequate method for predicting hypersonic boundary-layer transition are many and complex - a great deal of research and development still needs to be done before engineers will have a dependable predictive tool. 


\subsection{Viscous interactions}

The designers of vehicles that are to fly at hypersonic speeds have long recognized that the locally severe heating rates produced by viscous interactions and by shock/shock interactions can cause catastrophic failures. As noted earlier, one of the first in-flight confirmations of the severity of shock-impingement heating occurred in October 1967, when the X-15A-2 suffered severe damage to its ventral fin (pylon) during a high altitude flight at Mach 6.7.

The authors believe that the definitive treatise on shock/shock-interaction patterns was done by Edney. The complete presentation is given in the FFA report, Ref. [35]. A summary of this work is more generally available as Ref. [36]. Surface pressures, heat-transfer rates, and oil-flow patterns were obtained as symmetric models were injected into a hypersonic stream through a slot in a variable-incidence flat plate, which generated the impinging shock wave. The interaction between the impinging shock wave and the bow shock wave was found to be a function of the angle between the impinging shock wave and the bow shock wave. Edney $[35,36]$ found that there were six different shock/shockinteraction patterns. A sketch illustrating the approximate relation between the location where the impinging shock wave intersects the bow shock wave of a hemisphere and the shock/shock-interference patterns, as taken from Keyes and Hains [37], is reproduced in Fig. 6. Researchers have found that the impingement of a shear layer (Type III) or of a supersonic jet (Type IV) can produce locally severe heating rates. Heating rates in the impingement region can be more than an order of magnitude greater than the unperturbed values, i.e., than the heating rates that would exist in the absence of a shock/shock interaction.

Based on the damage to the ventral fin (pylon) of the X-15A-2 during the high-altitude flight at Mach 6.7, the shock/shock-interaction patterns became a known unknown. Thus, the phenomenon falls in the lower righthand quadrant of Knowledge Management Space of Fig. 1. Potentially severe heating rates to the wing leading edge, where the bow shock wave intersects the wing leading-edge shock wave concerned the designers of the Space Shuttle Orbiter. The sketch that is presented in Fig. 7 illustrates a potential shock/shock interaction between the bow shock wave and the wing leading-edge shock wave. As noted by Keyes and Hains [37], "Heating due to interfering shocks may also appear on the leading edge of wings and control surfaces depending on the amount of sweep." Bertin et al. [38] examined surface-pressure and heat-transfer-rate data for a variety of Shuttle Orbiter configurations over an angle-of-attack range from $0^{\circ}$ to $60^{\circ}$. The correlations for these three-dimensional flows indicated that the type of shock/shock-interaction pattern was dominated by

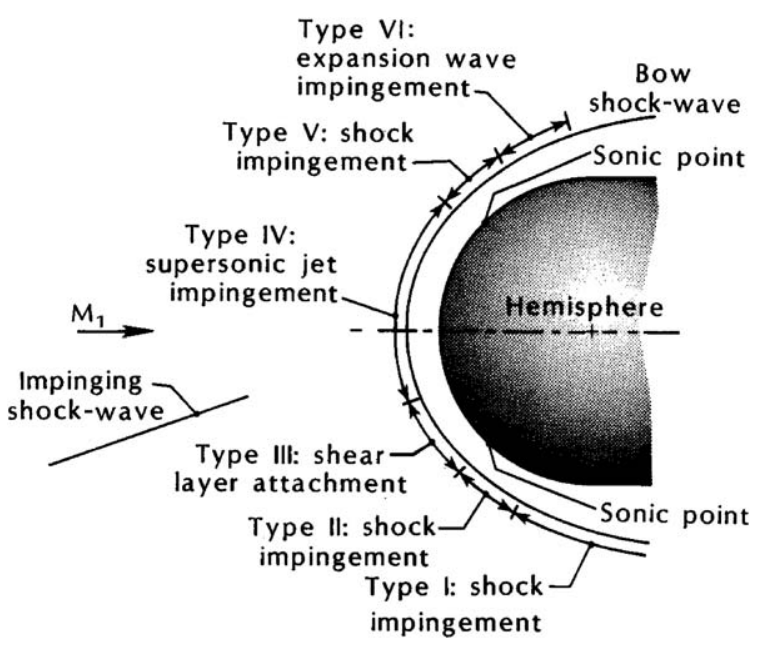

Fig. 6. Approximate Relation of the Shock/Shock Geometry and the Type of Interference Pattern Ref. [37].

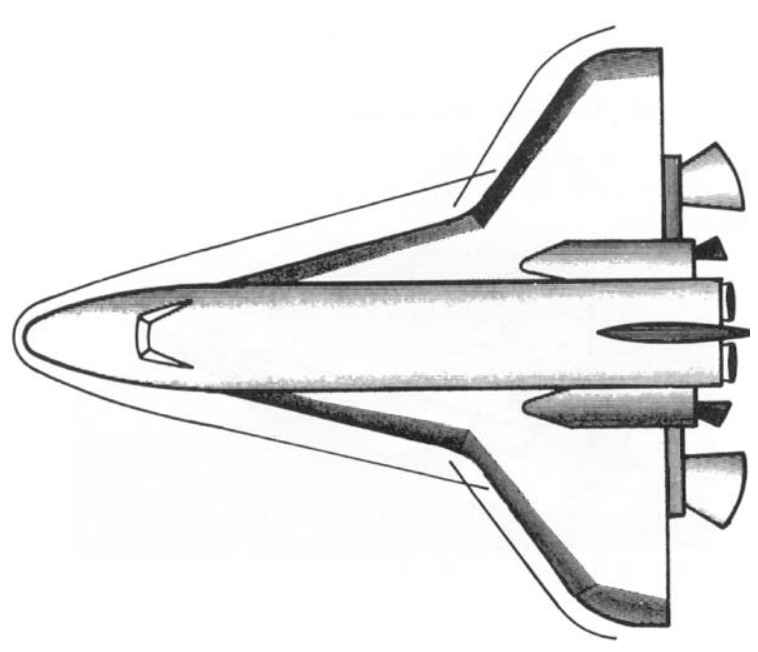

Fig. 7. Interactions Between the Bow Shock Wave and the Wing Leading-Edge Shock Wave for the Space Shuttle Orbiter Ref. [1].

the effective sweep angle of the wing leading edge. For the relatively low sweep angles of the straight-wing Orbiters (which were an early design option), the interaction between the bow-generated shock wave and the wing-generated shock wave exhibited the characteristics of a Type $\mathrm{V}$ shock/shock-interaction pattern. For delta-winged Orbiters, the shock/shock-interaction patterns exhibited the characteristics of a Type VI pattern for all angles-of-attack. The effect of gas properties, i.e., the use of the perfect-air model as opposed to the use of equilibrium air properties, was examined using numerical codes based on a shock-fitting scheme [39,40]. Using the equilibrium-air model to determine the real-gas 
properties, it was found that the minimum sweep angle for which a Type VI pattern existed decreased as the free-stream velocity increased.

Thomas et al. [41] identified critical aerothermodynamic design issues for a hypersonic aircraft powered by an air-breathing propulsion system. As indicated in the sketch presented in Fig. 8, the flow around a hypersonic aircraft is predominantly three dimensional and is dominated by viscous effects. In fact, every known type of viscous/inviscid interaction and shock/shock interaction has been identified by Thomas et al. as a design issue, i.e., as a known unknown.

Gaitonde and Shang [42] noted that the forebodies of proposed hypersonic aircraft that are powered by airbreathing propulsion systems form ramp-like structures designed to compress the incoming air with oblique shock waves. The forebodies, therefore, act as the compressor system for the inlet. "For optimum mass flow through the inlet, it is desirable that these compression system shocks, which may form a relatively strong oblique shock in conjunction with the vehicle bow shock, be positioned to converge on the inlet cowl leading edge where they interact with the bow shock produced by the cowl lip. Viscous hypersonic shock-onshock interactions (often denoted 'interfering' flows) can significantly affect the performance of the inlet through the creation of anomalous pressure and heat-transfer peaks on the cowl leading edge." The hypothetical hypersonic intake flow field depicted in the sketch of Stollery [43], which is reproduced in Fig. 9a, indicates that three shock waves interact on the cowl lip: (1) the "bow" shock wave produced by the cowl lip, (2) the bow shock wave originating at the vehicle leading edge, and (3) an oblique shock wave produced by the compressive turning of the flow by the inlet ramp. Most of the computations of the flow field for the cowl lip are based on the intersection of two shock waves: (1) the shock wave produced by the cowl lip and (2) the bow shock

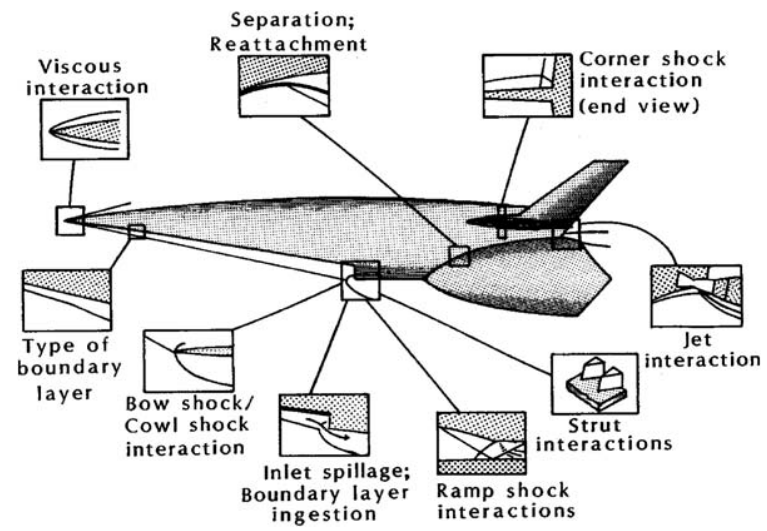

Fig. 8. Critical Design Issues for a Hypersonic Airbreathing Aircraft Ref. [41].

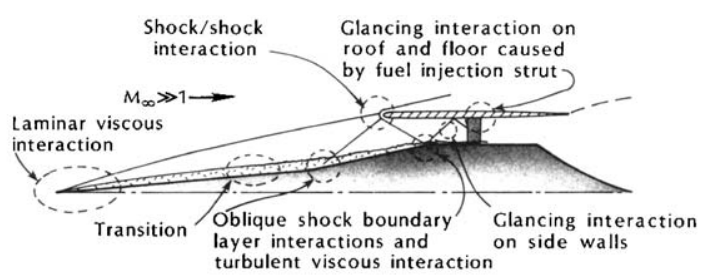

(a) Sketch of overall flowfield

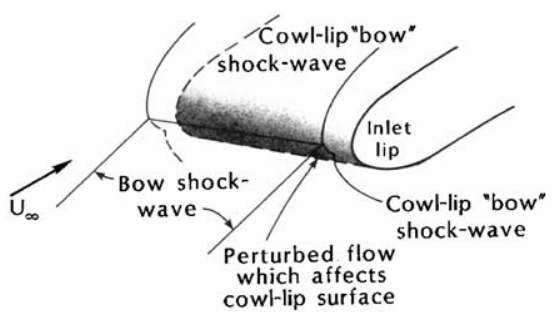

(b) Sketch of local flow, based on the presence of only two shock waves.

Fig. 9. Sketch of Flowfield Showing Typical Viscous Interactions Associated With Airbreathing Propulsion Systems Ref. [43].

wave originating at the vehicle leading edge. As indicated in the sketch of Fig. 9b, the interaction of these two shock waves produces a flow-field perturbation that affects the cowl-lip surface. The severity of the perturbation depends on where the impinging shock intersects the cowl lip shock wave; see Fig. 6.

The viscous/inviscid interactions and the shock/shock interactions described in this section can produce catastrophic failures. The designers of hypersonic vehicles often use conservative estimates of the effect of these phenomena in order to allow for the uncertainties in our understanding of them. However, too much conservatism may cause unacceptable weight penalties in the TPS or unacceptable restrictions on the allowable flight corridor.

\section{Propulsion systems and fuels}

The discussion of propulsion systems in this paper will be limited to rocket-powered propulsion systems (using either solid propellants or liquid propellants) and airbreathing propulsions systems. As noted by Billig [44]: "The choice of the propulsion system for a high-speed vehicle is dependent on numerous factors in addition to its efficiency as measured by the specific fuel consumption or its reciprocal, the fuel specific impulse. Among these factors are weight, complexity, variability, longevity and the cost of components, and the density, rheology, stowability, handling, combustion characteristics, cost of fuel." 


\subsection{The access-to-space mission}

In addition to the parameters itemized in the previous paragraph, the choice of whether to use an air-breathing propulsion system or a rocket-powered propulsion system may depend on the mission and on how the design team envisions the vehicle that will accomplish the mission. For instance, consider the access-to-space mission. The launch phase could be accomplished by horizontal take off or by vertical take off. Landing could be accomplished by horizontal landing or by vertical landing. Advantages of horizontal take off and horizontal landing include more versatile basing with airplane-like operations and launch offset capability. Common performance parameters for rocket propulsion systems include the specific impulse $\left(I_{\mathrm{sp}}\right)$, the thrust $(T)$, and the inert mass fraction $\left(f_{\text {inert }}\right)$, where

$f_{\text {inert }}=m_{\text {inert }} /\left(m_{\text {prop }}+m_{\text {inert }}\right)$.

Having values for all three parameters in the range suitable to accomplish the space-access mission with a single-stage vehicle is very challenging.

As pointed out in Ref. [45], a nuclear-rocket-propulsion system is similar to a liquid system, except for the mechanism that adds heat. A single propellant, usually hydrogen, resides in a tank. The propellant flows through the heat-addition section. A nuclear-fission reaction supplies heat to the propellant, which runs directly through a heat exchanger or over the heatproducing/fissioning material. The hot gases then expand through a conventional convergent/divergent nozzle. Several programs were pursued in the late 1940s through the 1960s to develop nuclear-rocket propulsion systems. Putnam [46] notes: "Typically, nuclear thermal rockets have good values for the specific impulse and for the thrust, but not for the inert mass fraction $\left(f_{\text {inert }}\right)$. The weights of the reactor core and of the radiation shield are the main cause for the high values of $f_{\text {inert }}$. Typical values for $f_{\text {inert }}$ of nuclear rocket designs are in the range of 0.5-0.7. By comparison, the X-33 was shooting for a value of $f_{\text {inert }}$ in the range of $0.02-0.03$ to achieve singlestage-to-orbit (SSTO). The technical disadvantages include the system complexity and the heavy weight of nuclear reactors. Furthermore, there is considerable political opposition to nuclear power.

As propellant is consumed, there is a commensurate decrease in the amount of tankage needed to store fuel. Since a low value for the inert mass fraction is desired, one would like to dispose of the unneeded inert mass continuously. The more practical approach is to wait until a fixed amount of fuel has been used and discard a large chunk of mass, which will be called a stage. Staging reduces the vehicle inert mass fraction, while increasing the cost, the complexity, and the reliability.

Therefore, while some design teams recommend single-stage-to-orbit (SSTO) vehicles or single-stage vehicles (SSVs), other teams propose the use of twostage-to-orbit (TSTO) vehicles. The advantages of multistage-to-orbit vehicles include a greater likelihood of having the required technology available in the near term. One disadvantage of the multi-stage-to-orbit concepts is the need to design three configurations: the launch vehicle, the orbiter, and the mated configuration.

Stanley and Piland [47] wrote: "To enable the design of an affordable single-stage vehicle (SSV), technologies and system design approaches must be utilized that decrease the operational complexity and empty weight of the vehicle, as shown in Fig. 10. Reductions in SSV empty weight and size have the potential to decrease vehicle development and production cost to some degree; however, the greatest benefit in reducing empty weight for an SSV occurs when the reduction in empty weight is traded for design margins. Increased vehicle margins can contribute to higher system reliability, lower attrition rates, improved crew safety, and decreased development and operational risk, thereby leading to a more affordable system." The propulsionrelated enhancing technologies for an SSV, as defined by Stanley and Piland [47], include a new hydrogen propulsion system that would be operationally more efficient than Space Shuttle Main Engine (SSME) derivatives and the use of a hydrocarbon fuel during the early phases of an SSV ascent trajectory. The use of duel fuel designs has been incorporated in many of the hypersonic vehicle concepts proposed from 1988, or later. Thus, the improvements in technology that are the focus of Fig. 10 correspond to the upper two quadrants in Fig. 1, where we conduct targeted research into known unknowns or seek to apply technologies that are well-developed to new applications.

As noted by Orton et al. [48]: "The SSTO solution, if it can be achieved, provides great advantages in launch system architecture and flexibility. Elimination of staging results in a smaller vehicle at launch than is the case for any staged option, and the reusability of the
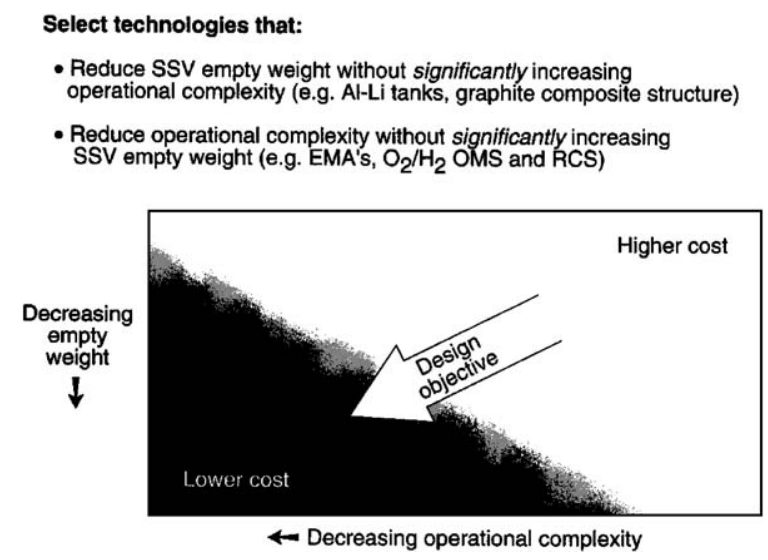

Fig. 10. Technology Selection Process Ref. [47]. 
entire vehicle simplifies launch system logistics. These advantages exist whether the vehicle is airbreathing or rocket powered, because in either case the SSTO approach will result in the smallest overall vehicle size. In the special case of the airbreathing vehicle, the SSTO approach becomes more compelling, because the separation problems inherent in a multistage approach become more difficult at the high dynamic pressures required by an airbreathing vehicle."

The TSTO-vehicle classification proposed by Hunt et al. [49] is reproduced in Fig. 11. Even with a rocketpowered booster, the propulsion system for the orbiter of one classification combines "scramjet-rocket" systems for the orbiter. With their ability to cruise, air-breathing boosters have the potential to return to viable landing sites, even at the higher staging Mach numbers. Nevertheless, many of today's launch providers favor concepts that utilize rocket power both for the booster and for the orbiter. Two-stage-to-orbit designs are attractive because of their technology readiness levels. However, there are a number of hypersonic concepts that employ a combination of rocket propulsion and air-breathing propulsion systems. They include the German Saenger Space Transportation System [50] and the Beta concept [51]. Gord et al. [51] proposed a fully-reusable two-stage vehicle capable of horizontal take off and horizontal landing. The first stage (booster) employs a multicycle high-Mach-number air-breathing propulsion system complemented by conventional rocket propulsion, as required. The second stage (orbiter) is a high lift-todrag-ratio design with a dedicated high-volume payload bay, powered by a conventional rocket engine.

Designers of TSTO systems select the orbiter staging Mach number based on several interrelated criteria, which include the theoretical velocity potential $(\Delta V)$ capable of being built into the orbiter, the requirements for realistic, near-term air-breathing and rocket-propulsion systems for the booster and for the orbiter components, respectively, and the thrust-to-weight ratio of the orbiter at staging. The second-stage weight is presented as a function of the theoretical velocity potential $(\Delta V)$ in Fig. 12, which is taken from Ref. [51]. Marked on the curve for reference are the orbiter velocity inputs required to reach a $185 \mathrm{~km}(100 \mathrm{n} . \mathrm{mi}$.) polar orbit for staging Mach numbers of $0.8,6.0$, and 8.0. Note that the orbiter weight increases rapidly as the staging Mach number drops below about 6.

For launch systems that employ boosters powered by air-breathing propulsion systems, Hunt et al. [49] state that: "For launch systems that stage at Mach 6 or below, the booster could be designed with near term technology. Boosters that stage above Mach 6 would require more advanced technology because of the need for a scramjet and more sophisticated/thicker TPS." Returning to Fig. 12, the orbiter would weigh approximately 2.45 million $\mathrm{N}(550,000 \mathrm{lb})$, if staging occurred at Mach 8. However, to stage at this Mach number requires that the air-breathing propulsion system include a scramjet, since Mach 6 is the approximate limit for operating a ramjet. Use of a turboaccelerator, i.e., a turbojet propulsion system, simplifies the design requirements on the air-breathing propulsion system, but limits the Mach number to 4 . Referring to Fig. 12, a staging Mach number of 4 results in an orbiter weighing approximately 4.45 million $\mathrm{N}$ ( 1 million $\mathrm{lb}$ ).

The thrust-to-weight ratio is an important parameter in relation to the systems ability to achieve orbit. Since the rocket-propulsion system of the orbiter was a derivative of the Space Shuttle Main Engine (SSME), the assumed specific impulse $\left(I_{\mathrm{sp}}\right)$ was 464 seconds and

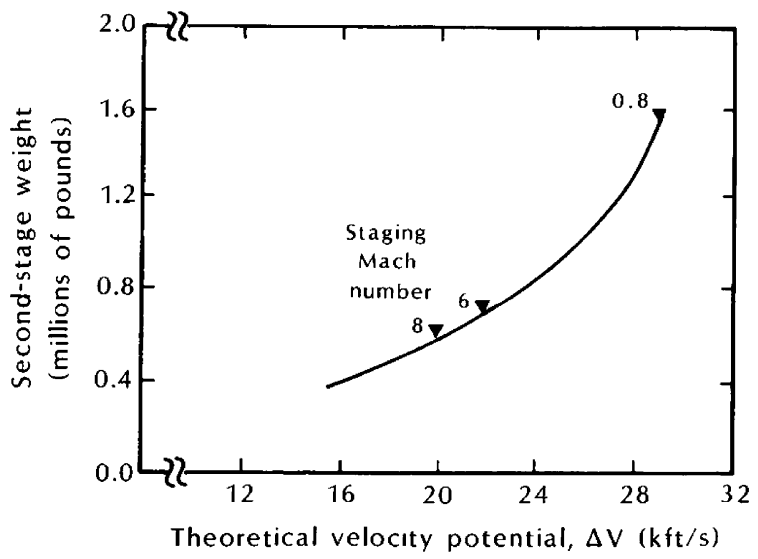

Fig. 12. The Second-Stage (Orbiter) Weight as a Function of $\Delta V$ for a 50,000 lb. Payload Ref. [51].

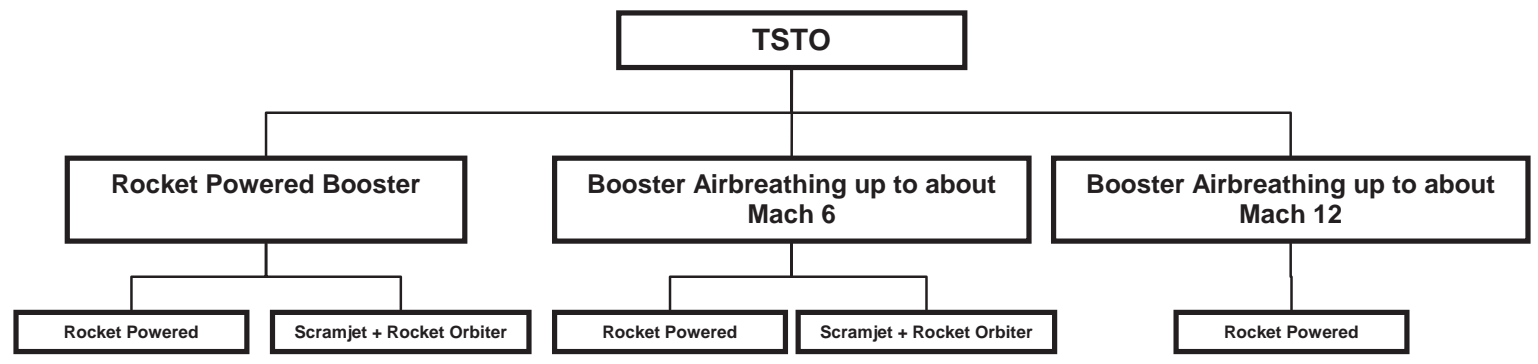

Fig. 11. TSTO Vehicle Classification Ref. [49]. 
the vacuum thrust rating was 2.3 million $\mathrm{N}(516,000 \mathrm{lb})$. Thus, the thrust-to-weight ratio for Mach 8 staging is adequate to achieve orbit with a single SSME. However, for staging at Mach 6, the orbiter is too heavy for a single SSME, resulting in a more complicated orbiter propulsion system. Such design trade studies are knowledge re-use, i.e., the upper right-hand quadrant in Fig. 1.

\subsection{Air-breathing propulsion systems}

In designing a vehicle that is to fly at hypersonic speeds while powered by an air-breathing propulsion system, one must simultaneously consider the aerothermodynamic environment, the propulsion system, the structure (including structural dynamics), and the flight control system in the design of the vehicle. As noted, by Blankson [52], "The technical problems are multidisciplinary to first order. Proper resolution of these problems requires the ability to integrate highly-coupled and interacting elements in a fundamental and optimal fashion to achieve the desired system performance."

The total enthalpy (and to a limit, the total temperature) of the flow increases as the square of the flight velocity. The air decelerates to accommodate the combustion processes in the turboaccelerator. The temperature of the air increases as it passes through the combustion chamber flow path. Thus, the temperatures that occur in the combustion chambers of turbojet concepts limit the Mach number range for which these concepts can be used. For Mach numbers in excess of those for which turbojet concepts can be used, subsonicburning ramjet concepts can be used until their Mach number limit is reached. Finally, the aircraft achieves Mach numbers for which the temperatures in the combustion chambers of the ramjet concepts are excessive and supersonic combustion ramjets (scramjets) must be employed. Orton et al. [48] note: "Low-speed propulsion (Mach 0-6) is the single technology area that may pace the development of hypersonic cruise vehicles because it requires the development of turbomachinery that can operate at high temperatures. Advanced turbojet concepts are being pursued for operation to Mach 4. Also, several advanced turboramjet concepts are candidate systems for operation to Mach 6. These are axisymmetric flow path designs. Ram-scramjets and scramjets alone are used for higher speed flight and operate in a separate flowpath from the low-speed engine package. Transition from ramjet operation to scramjet occurs at about Mach 6 by adjusting the variable geometry propulsion flowpath." Curran et al. [53] note: "Obviously it is desirable to extend the performance of a scramjet over the widest possible range of Mach numbers to reduce the complexity of the lower-speed propulsion system. It is also strongly desirable to avoid the complexity of variable-geometry operation."
The approximate specific impulse for various engine cycles using either hydrogen or hydrocarbons as the fuel are presented in Fig. 13. The specific impulse for turbojets, for subsonic combustion ramjets, for supersonic combustion ramjets, i.e., scramjets, and for rockets are presented as a function of Mach number. It is apparent that, as the flight speed increases, the turboaccelerator class of engine is supplanted first by the subsonic combustion ramjet and then by the supersonic combustion ramjet. Rocket propulsion may also be needed at the higher flight speeds. Consequently, for a hypersonic flight vehicle that operates at a maximum speed of up to approximately Mach 7 or greater, a multimode propulsion system will be required. Bearing in mind the limitations of materials, such an engine system might operate as a turboaccelerator to speeds of the order of Mach 4.0, then transition to a subsonic ramjet operation up to speeds of the order of Mach 6.0, and then be operating totally as a supersonic combustion engine for speeds above about Mach 7.0.

Foster et al. [54] note: “' 'Combined Cycle Engines' functionally and physically integrate more than one propulsion engine cycle into a single engine assembly. They should not be confused with 'combined cycle vehicles', 'combination propulsion systems', 'multicycle' propulsion or 'Multi-Mode Vehicles' having more than one physically separate propulsion cycle in a single vehicle."

Possible rocket-based combined-cycle (RBCC) engine systems in SSTO vehicles transition from air-augmented rocket (ejector) mode, providing initial acceleration, to ramjet mode, to scramjet mode and finally to all rocketpropulsion for final orbit insertion. Such engines are capable of providing on-orbit propulsion for orbit change, powered descent including cross range maneuvers, and powered landing, either horizontal or vertical, with go-around capability.

Curran [55] wrote: "It is clear that for maximum flight speeds of about Mach 6 the use of a conventional ramjet cycle is imperative and for higher maximum flight speeds

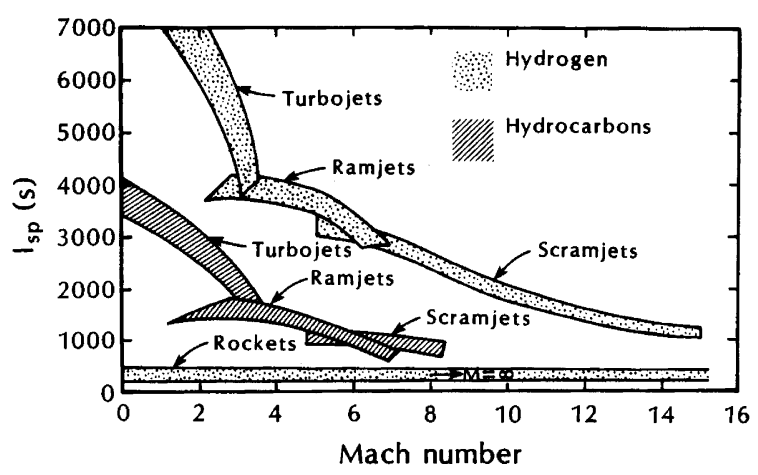

Fig. 13. Specific Impulse for Various Propulsion Devices Fueled by Hydrogen or by Hydrocarbons Ref. [1]. 
the scramjet is the appropriate high speed engine. The lower speed engine cycle must be integrated with the appropriate ramjet elements to form a truly combined cycle engine. In the following discussion the term low speed engine applies typically to turboaccelerator or rocket-based systems used to accelerate the vehicle up to speeds of roughly Mach 4.0."

"For purposes of discussion, let us consider a hypersonic vehicle with maximum speed in excess of say Mach 7, and consequently using a supersonic combustion ramjet as its dominant propulsion system. A plausible overall propulsion installation for such a vehicle is one which uses a low speed engine of the turboaccelerator class for take-off (and landing), and for acceleration to speeds of about Mach 4.0, followed by an initial transition to ramjet operation. A subsequent transition to scramjet operation takes place at about Mach 6.0. The vehicle then accelerates to a terminal Mach number on scramjet power."

Curran [55] continued: "It is appropriate to point out that because of the complexities of mode transition, there is a substantial payoff to eliminating such transitions. For example, the turboaccelerator speed capability may be 'stretched' to permit direct transition to a scramjet mode. Alternatively, for say a Mach 7 system, the ramjet performance may be 'stretched' to avoid transition to a true scramjet mode. Simultaneously the scramjet take-over Mach number may be reduced or 'stretched' down to eliminate the ramjet mode."

\subsection{Fuels}

For purposes of discussion, fuels that can be used for air-breathing hypersonic vehicles will be divided into two classes: hydrocarbons and liquid hydrogen. The characteristic properties of these two fuels are summarized in Table 2, which is taken from Ref. [56]. Hydrogen is attractive because it can be used to cool the internal (engine) and external flow surfaces, or to cool the air and thus impact the engine's thermodynamic cycle. However, because of the low density of liquid hydrogen, hydrogen-fueled vehicles require large tankage volumes. The large tankage volumes may result in an excessive cross section (with the attendant pressure drag) or excessive surface area (with the attendant skin-friction

Table 2

Comparison of fuel characteristics, as taken from Ref. [56]

\begin{tabular}{lll}
\hline Property & Hydrocarbon & Hydrogen \\
\hline Heat of combustion $(\mathrm{J} / \mathrm{kg})$ & $44 \times 10^{6}$ & $118 \times 10^{6}$ \\
Specific heat $(\mathrm{J} / \mathrm{kg} / \mathrm{K})$ & 1926 & $11307-15495$ \\
Liquid density $\left(\mathrm{kg} / \mathrm{m}^{3}\right)$ & 817 & 72 \\
Boiling temperature at & $456-508$ & 20 \\
$\quad 1$ atm $(\mathrm{K})$ & & \\
\hline
\end{tabular}

drag, surface heating, and vehicle weight). Another disadvantage is the boiling point of liquid hydrogen, which is $20 \mathrm{~K}\left(36^{\circ} \mathrm{R}\right)$. Therefore, the fuel must be carried in cryogenic tanks, creating logistics problems.

For certain applications, endothermic hydrocarbon fuels can be considered as an alternative fuel. As indicated in Table 2, hydrocarbon fuels have higher boiling points, so they are storable. However, since they have a significantly lower heat capacity, they may not provide sufficient cooling for the vehicle surfaces for Mach numbers above 7 or 8 . Referring to Fig. 13, the reader can see that the specific impulse for the systems using endothermic hydrocarbon fuels is roughly onethird of that for the corresponding hydrogen-fueled system. However, because the density is larger, hydrocarbon fuels require less storage volume. Thus, vehicles using hydrocarbon fuels have smaller cross sections and less surface area. As a result, configurations with lower drag can be developed. Referring to the Breguet equation, the reduced specific impulse and the reduced drag are compensating parameters when calculating the range.

Thus, Hunt et al. [49] conclude: that, if the fuel to be used in hypersonic vehicles powered by air-breathing propulsion systems is to be an endothermic hydrocarbon fuel, flight speeds will be limited to a Mach number of eight, or less. Hydrogen-fueled vehicles can fly over the entire Mach number range. However, the shape of the vehicle and the systems that constitute it will be considerably different for hydrocarbon-fueled machines than for hydrogen-fueled machines, because of the fueldensity differences and the resultant planform required to accommodate loading. Thus, the designers would probably choose to use endothermic hydrocarbons as the fuel for vehicles designed to fly at Mach numbers of eight, or less. For those vehicles designed to exceed Mach eight, the hybrid, dual-fuel approach offers considerable advantages. Bogar et al. [57] explain: "The term dual fuel refers to the fact that endothermic hydrocarbon fuel is used for the turbine engine lowspeed propulsion system, and cryogenic hydrogen for the ram/scramjet high-speed propulsion system." However, Curran [55] recommends "Similarly in relation to fuels it is desirable where possible to stretch the performance of hydrocarbon class fuels to higher Mach numbers to defer the logistical problems of operating with cryogenic fuels. Consequently the propulsion engineer must place emphasis on 'stretched' capability wherever appropriate, and where mission requirements will not be compromised."

\subsection{Ascent flight}

As noted by Freeman and Wurster [58]: "Until the rebirth of the emphasis on air breathing propulsion resulting from the advent of the National Aero-Space 
Plane Concept, ascent hypersonic flight was not a vehicle design driver. For the rocket systems currently operational, the aerodynamic loads which design the structure occur during transonic flight and the aerodynamic heating limits are either low enough to be insignificant or established for the reentry flight regime. There is a significant difference in the way the two vehicles fly. The rocket system very quickly achieves altitudes that reduce the loads and aerodynamic heating, whereas the air-breathing system must operate at lower attitudes to maintain higher dynamic pressure for maximum engine performance. The difference in these ascent trajectories make hypersonic flight a major part of air-breather vehicle design, whereas the rocket system is fairly insensitive to hypersonic flight. For the airbreathing vehicle design which operates at high dynamic pressures for extended periods of time, the aerodynamic performance and the total surface heating are major vehicle design drivers. The other major difference between the air-breather and rocket vehicle design is the added complexity of interaction between the air frame and propulsion system for the air-breather approach."

\subsection{Design}

Hunt et al. [49] note: "Other than the fuel, the biggest influence on the system architectures will come from engine integration. All hypersonic airplanes considered herein are engine-airframe integrated in that the forebody serves as an external precompression surface for the engine inlet and the aftbody as a high expansion ratio nozzle. Also, for the purpose of discussion continuity, the airbreathing propulsion flow path is considered on the lower surface of the vehicle (underslung). The differences are in whether the engine integration embodies a single duct or a two-duct approach."

Clearly, the designers of a hypersonic vehicle, which is powered by an air-breathing propulsion system, face many challenging problems. Many of the problems are in the two lower quadrants of the Knowledge Management Domain depicted in Fig. 1. Not only are the known unknowns well-beyond the current state-of-theart, but the possibility exists that there are unknown unknowns.

To help develop the technology base for the airbreathing propulsion systems for hypersonic systems, NASA initiated the Hyper-X Program in the 1990s. As discussed by McClinton et al. [59]: "The goal of the Hyper-X Program is to demonstrate and validate the technology, the experimental techniques, and computational methods and tools for design and performance prediction of hypersonic aircraft with airframe-integrated hydrogen-fueled, dual mode combustion scramjet propulsion systems. Accomplishing this goal requires flight demonstration of and data from a hydrogen-fueled scramjet powered hypersonic aircraft."

McClinton et al. [59] further state: "The Hyper-X Program concentrates on three main objectives required to significantly advance the Mach 5 to 10 scramjet technology leading to practical hypersonic flight:

1. vehicle design and flight test risk reduction-i.e., preflight analytical and experimental verification of the predicted aerodynamic, propulsive, structural, and integrated air-vehicle system performance and operability of the Hyper-X Research Vehicle (HXRV),

2. flight validation of design methods, and

3. methods enhancements - i.e., continued development of the advanced tools required to refine scramjetpowered vehicle designs.

"These objectives include experimental, analytical, and numerical (CFD) activities applied to design the research vehicle and scramjet engine; wind tunnel verification of the vehicle aerodynamic, propulsion, and propulsion-airframe integration, performance and operability, vehicle aerodynamic data base and thermal loads development; thermal structural design; boundary layer transition analysis and control; flight control law development; and flight simulation model development." McClinton et al. [59] conclude: "Flight data will be utilized to verify design methods, the wind tunnel methods and the overall utility of a scramjet powered vehicle."

Unfortunately, the first flight-test attempt, that was conducted in June 2001, ended prematurely in a failure during the rocket-assisted boost to the scramjet test condition [60]. At the time this paper is being written, the two additional X-43 vehicles have not been flown.

\section{Structures and materials}

Vehicles that fly at hypersonic speeds will be exposed to severe aerothermodynamic environments. The severity of the environment and the length of time that the vehicle will be exposed to this environment depend on the flight Mach number and the mission profile. The temperature/time requirements for oxidation-resistant materials in aerospace propulsion systems, which was presented in Ref. [61], has been reproduced in Fig. 14. The figure was originally presented in Ref. [62]. To survive in these harsh environments, the materials from which the vehicle is made must be high-strength materials capable of surviving high temperatures in an oxidizing environment with severe acoustic loads. However, they should be light weight and, for most applications, they must be reusable. Orton et al. [48] 


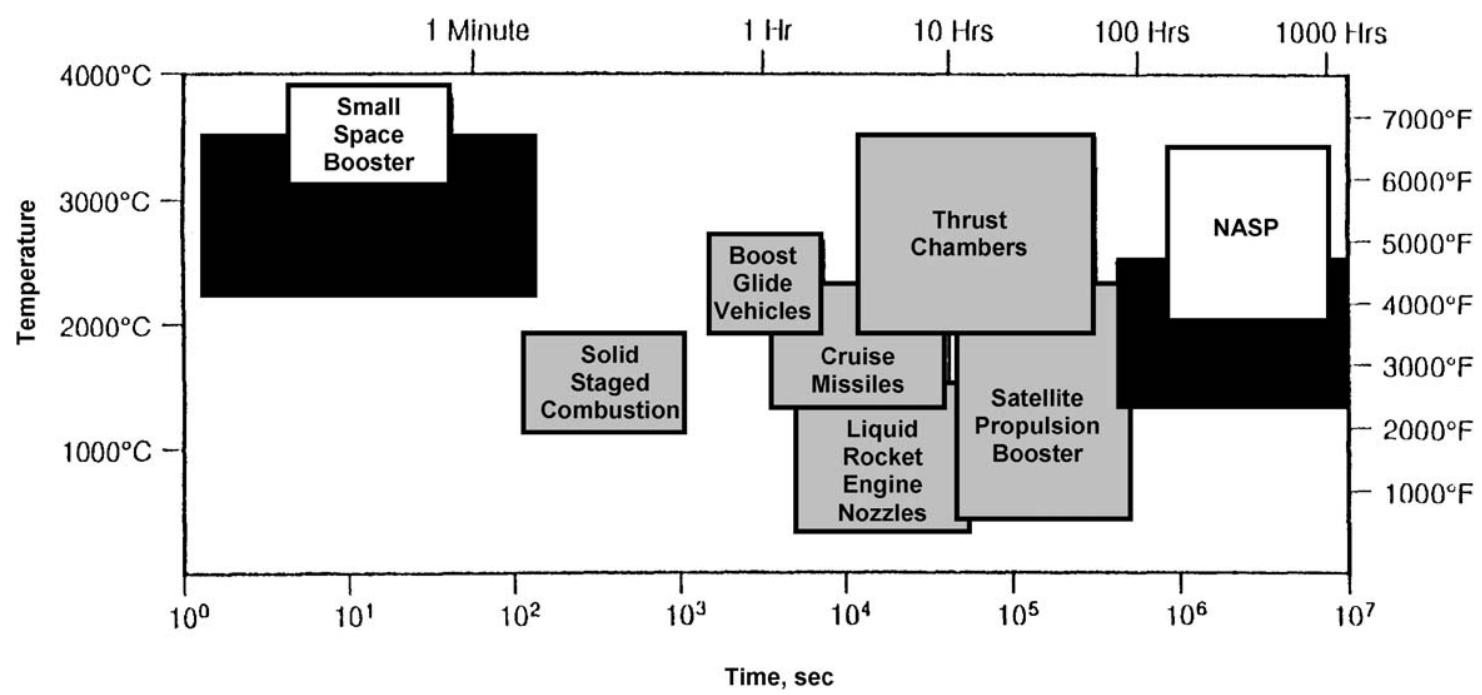

Fig. 14. Materials Requirements: time-temperature requirements for oxidation resistant materials in aerospace propulsion systems Ref. [61].

note that: "Advanced materials include fiber composites, titanium-based alloys, titanium-aluminides, titanium matrix composites, and carbon-carbon. Some are available although others require further development. For example, an extensive titanium matrix composite (TMC) database was produced as part of the NASP program."

Advances in our understanding of the physical and of the chemical processes that are the foundation of developing new materials and in the numerical models that we use to generate computational procedures to execute the desired processes allow us to manufacture new materials, which have the desired properties. However, the process may be limited to producing coupon-sized specimens. While the coupon-sized specimens may be large enough that their properties can be determined from tests that are conducted in groundbased facilities, such as arc jets and radiant lamp facilities, it may happen that one is never able to fabricate the material in sizes suitable for use in building a vehicle. Advanced manufacturing techniques are required to fabricate the tooling, subcomponents, and large structure assemblies necessary to build a full-scale vehicle. These techniques include advanced processing, extensive use of robotics, and effective design of large components and assemblies with limited fasteners. The critical space in the Knowledge Management Domain of Fig. 1 is the ability to extend successes in developing a coupon-sized specimen of a new material with the desired properties to fabricating structures of sufficient size and strength, which can be used to build the vehicle.

Improvements in structures, materials, and manufacturing technology accommodate the development of light-weight, high-strength materials that can be effi- ciently manufactured into structures capable of withstanding the hypersonic environment. The benefits of developing such materials and their applications to producible, durable structures include: (1) reduced manufacturing lead time, (2) reduced vehicle costs, (3) increased launch capability, and (4) improved reliability and increased safety/operational margins. Advances in structures and materials must be achieved in:

1. reusable tanks for storing cryogenic fuels,

2. advanced thermal protection systems, and

3. load carrying structures.

Schweikart [61] discussed the problems relating to the timely development of materials for the National Aerospace Plane (NASP). "Materials raised particular concerns about timely development. In many ways, despite the fact that the integrated design and scramjet operation stood as daunting challenges, virtually every aspect of the technology-including performance, temperature and pressure sustainability, and weight savings - depended in some way on the timely arrival of a wide array of new materials. NASP research into a variety of new materials, including the heat tiles on the Space Shuttle, found that substantially new materials took an average of 10-15 years to develop, but NASP assumed that the program could get its critical new materials on line in five years. Internal DoD reviews expressed concern that the program would pass critical decision points before needed data became available."

\subsection{Propellant tanks}

Stanley and Piland [47] suggest: "Light-weight reusable cryogenic propellant tanks are critical to the 
design of an affordable SSV. The current state-of-the-art cryogenic tank structural material for aerospace vehicles is aluminum (Al), all current flight-weight cryogenic tanks are expendable. Hence, little experience base exists in the certification, inspection, and maintenance of reusable, flight-weight tanks in the operational pressure range of an SSV. If SSV propellant tanks utilize similar pressures to those of the External Tank of the current space transportation system (STS), the use of Al-Li 2095 could reduce the weight of the main propellant tanks 10-15\% below those designed with Al 2219. More advanced graphite composite hydrogen tanks under study by the NASP program offer the potential for even larger weight reductions; however, considerable testing would be required to determine the suitability of graphite composites for $\mathrm{LH}_{2}$ containment at the operational pressures of an SSV and to determine methods for inspection, maintenance, and repair." This last sentence is especially meaningful in view of the problems that arose with the X-33 tanks. Recall the 1997 explosion of the propellant tank on a test stand.

\subsection{Thermal protection systems (TPS)}

The aerothermodynamic environment for a vehicle flying at hypersonic speeds is sufficiently severe that a thermal protection system is required to maintain suitable limits for the temperature of the load-carrying structure. The type of TPS that is required depends both on the heat-transfer rate and on the heat-transfer load (the integral of the heat-transfer rate over the time of flight). The design and the actual heat-transfer rates and heat-transfer loads for the reentry vehicles from the manned spacecraft programs, as presented by Curry

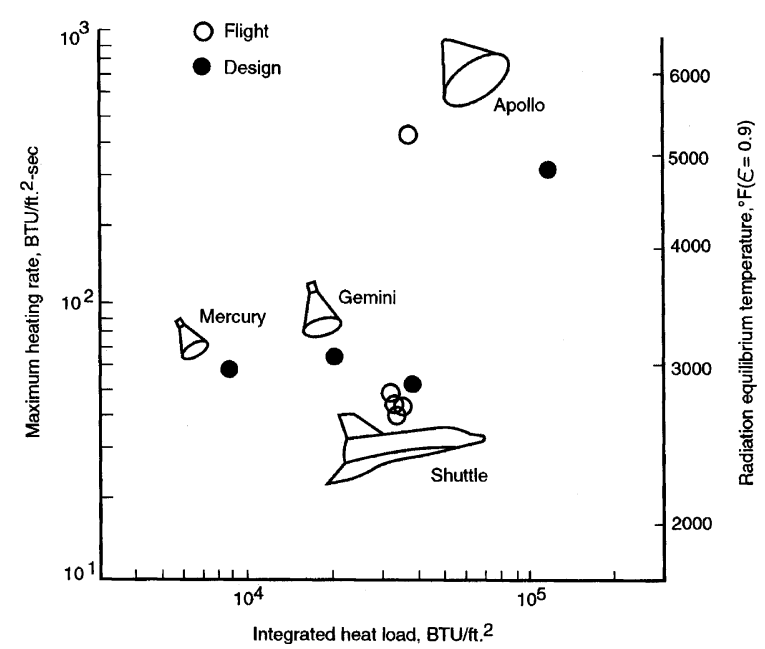

Fig. 15. TPS Design and Flight Test Environments Ref. [63].
[63], are reproduced in Fig. 15. Since the stagnationpoint convective heating rate varies as the flight velocity cubed [see Eq. (5)] and since radiative heating becomes a factor for a capsule entering the earth's atmosphere at superorbital reentry speeds [see Eq. (6)], the Apollo Command Module is subjected to extremely high heating rates. The design value of the maximum heating rate was a factor of five greater than those experienced during the Mercury and the Gemini programs. Note also that there is a large difference between the design integrated heat load and the flight value. The designers of the Apollo Command Module had to deal with large uncertainties in predicting the aerothermodynamic environment and in the response of the ablative thermal protection system to that environment. Thus, the design procedures incorporated considerable margins of safety to allow for these uncertainties.

Kelly and Blosser [64] divide TPS concepts into one of three broad categories: passive, semipassive (or semiactive), and active. As shown in Fig. 16, passive concepts have no working fluid to remove the heat. Although semipassive systems have a working fluid that removes the heat, they require no external system to provide or to circulate the coolant that removes the heat. Active concepts have an external system that provides coolant during the flight to remove heat from the structure or to prevent it from reaching the structure. The concepts, as presented in Fig. 16, are arranged in approximate order of increasing capability. Because the incident heating rates in one region of the hypersonic vehicle may be an order of magnitude higher than those in another region, several different types of TPS may be used to protect different regions of the same vehicle.

For a passive system, the incident heating is accommodated by increasing the temperature of the TPS material (serves as a heat sink), by conducting heat away from the surface of the TPS (serves as a conductor/ insulator), and/or by reradiating the energy back into the surrounding flow field. For relatively short-duration heat pulses, it may be possible to use a large thermal mass of a high conductivity material to absorb most of the incident heat, storing it in the structure. To keep the incident heating as small as possible, the nose radius would be as large as practical. Such a passive TPS system would be a heat-sink structure.

The TPS of the Space Shuttle Orbiter has several variations on the concept of an insulated structure. Reusable surface insulation (RSI) was represented by three rigid ceramic insulation materials [63]:

1. high-temperature reusable surface insulation (HRSI) consisting of black-coated LI-900 and LI-2200 tiles,

2. low-temperature reusable surface insulation (LRSI) consisting of white-coated LI-900 tiles, and

3. fibrous refractory composite insulation (FRCI-12) with black coating. 


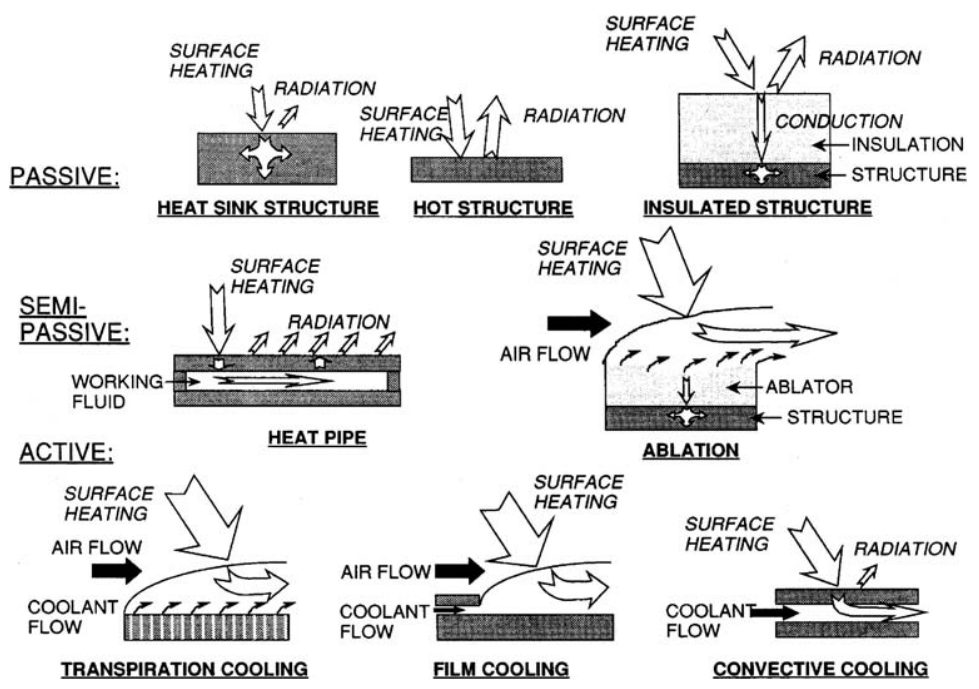

Fig. 16. Thermal Protection System Concepts Ref. [64].

The Shuttle RSI included two flexible insulation materials:

1. flexible reusable surface insulation (FRSI) and

2. advanced flexible reusable surface insulation material (AFRSI).

Reinforced carbon/carbon (RCC) was used to protect those areas of the Space Shuttle Orbiter where the surface temperature was expected to exceed $1530 \mathrm{~K}\left(2294^{\circ} \mathrm{F}\right)$, i.e., the nose cap and the wing leading edges. Reinforced carbon/carbon is an example of a hot structure sub-type of a passive TPS concept, see Fig. 16. For a hot structure design, the temperature of the structure increases until it reaches the radiation equilibrium temperature, i.e., the amount of energy radiated from the surface just balances the incident heating. This concept is not limited by the duration of the heat pulse, but is limited by the by the maximum temperature for which the proposed material retains its desired properties.

The nose cap and the wing leading edges of the Space Shuttle Orbiter are of relatively large radii, keeping the incident heating sufficiently low so that RCC surfaces can be used. However, for a hypersonic aircraft that is to cruise at Mach 10, there is a critical trade study. The leading-edge radii must be sufficiently small so that the drag is not excessive, but large enough to maintain the heating rates within tolerable limits.

Improved hot-structure concepts for thermal protection systems require advancements in the following classes of materials: (1) organic composites, such as carbon-carbon composites; (2) metal matrix composites (MMC), such as titanium-aluminide alloys; and (3) ceramic matrix composites (CMC), such as those with silicon nitride or silicon carbide. CMCs offer improved thermal efficiency and reduced component weight in these high-temperature environments. However, CMC can be considered among the most embryonic of these composite materials. In addition to being expensive and difficult to fabricate, there is only limited experience with these materials. Rasky reported [65] that researchers at the Ames Research Center (NASA) have developed very high-temperature zirconium-based and hafnium-based CMCs. Tests have revealed that diborides of zirconium $\left(\mathrm{ZrB}_{2}\right)$ and of hafnium $\left(\mathrm{HfB}_{2}\right)$ were the most oxidation-resistant of the high-temperature materials studied. Arc-jet tests of these materials demonstrated that they could survive heating rates over two times the capacity of RCC specimens and could survive temperatures in excess of $2500 \mathrm{~K}\left(4040^{\circ} \mathrm{F}\right)$.

However, it would be well to recall that the results obtained from arc-jet tests of a coupon-sized specimen do not guarantee that the material can be used to manufacture a structure of sufficient size and strength to produce a wing leading-edge that can withstand the rigors of hypersonic flight. Even then one must develop procedures for inspection, maintenance, and repair to support the operational vehicle. These tasks require both prospecting (hunting and searching) and targeted research in the Knowledge Management Domain of Fig. 1.

For reentry vehicles that experience relatively mild aerothermodynamic environments, a passive thermal protection system is the most weight efficient and, generally, the safest. According to Goldstein [66]: "Passive insulation systems can be divided into two groups: the load carrying hot structure type of TPS, such as carbon/carbon, which requires an insulator under it to protect the cold structure, and the surface insulation which is nonload carrying but transmits the 
aerodynamic loads through a strain isolator and is itself the thermal protection system."

As shown in Fig. 16, semipassive (or semiactive) thermal protection systems include heat pipes and ablators. A heat pipe is a self-contained, two-phase heat-transfer device, which is composed of a container, a wick, and a working fluid. Heat pipes are attractive for applications where there is a localized area of high heating with an adjacent area of low heating (such that the surface temperature is below the radiation equilibrium temperature for the heat pipe material). Heat is absorbed by the working fluid in the heat pipe at the highly heated end. The absorbed heat vaporizes the working fluid. The resulting vapor flows to the cooler end of the heat pipe, where it condenses and the stored heat is rejected. The condensed working fluid is returned through the wick to the high temperature end of the heat pipe by capillary action. Ablative TPS are used to protect hypersonic vehicles exposed to extremely high heating rates. Initially, the incident energy is conducted inward and is absorbed by the ablator, increasing its temperature until chemical reactions pyrolyze the ablator, leaving a layer of porous char between the outer surface and the pyrolysis zone, where the chemical reactions are taking place. The pyrolysis gases percolate to the surface, absorbing energy as they pass through the char, blocking a fraction of the incident heat as they are injected into the boundary layer. Since the more severe the aerothermodynamic environment, the greater the blockage of the incident heating by the transpiring gases, ablators are considered self-regulating systems. On the negative side, the transpiring gases and the roughened charred surface promote boundary-layer transition (if it does not occur naturally). Prior to the STS, all manned reentry vehicles used ablative TPS materials, having a one-mission capability.

Three active cooling concepts are presented in Fig. 16. Both for transpiration cooling and for film cooling, coolant passes through the surface, blocking much of the incident aerodynamic heating from reaching the surface. These two concepts use an external pumping system to bring coolant from a remote reservoir and to eject it through the surface into the boundary layer. For transpiration cooling, the coolant is injected perpendicular to a porous surface. For film cooling, the coolant is injected essentially parallel to the surface from discrete slots. The weight and the costs of the piping, the controls, and the expendable coolant itself discourage the designer from using either transpiration cooling or film cooling, except for application to small regions of the vehicle, which are subjected to severe heating rates.

Convective cooling is a method of limiting structural temperatures by circulating a coolant through the vehicle structure. Convective (or active) cooling is a common design feature for launch systems, which are powered by an air-breathing propulsion system. If the fuel is used as the coolant, the fuel heat-sink capacity is a critical parameter. Thus, the high heat-sink capacity of hydrogen compensates for its relatively low density (large specific volume). The high density of endothermic hydrocarbons compensates for its relatively low heatsink capacity. In the direct cooling system of a vehicle that uses liquid hydrogen as a fuel, the hydrogen fuel flows directly through the surface to be cooled on its way to the engine, where it is burned as fuel. In the indirect system, a secondary coolant (which may be a more easily pumped liquid than hydrogen) circulates through the surface to be cooled and then through a heat exchanger, where the heat absorbed in the first step is transferred to the hydrogen fuel.

The guidelines recommended by Hunt et al. [49] for a hypersonic aircraft designed to cruise in the Mach 10 range stated that the engine cowl, sidewall, and vehicle leading edges should be actively cooled. The engine cowl leading edge is a particularly difficult problem, because of the possibility of extreme heating in the event that the bow shock wave impinges on the cowl lip. The wing leading edges would be made of ceramic matrix composites such as zirconium diboride or coated carbon/carbon.

Kelly and Blosser [64] reported the results from experiments in which convective cooling was used to protect test panels from a severe aerothermodynamic environment. It was concluded that: "Material properties, which are sometimes considered secondary (such as: conductivity, thermal expansion, ductility, fracture toughness, etc.) assume primary importance because of the impact of heat transfer and the wide range of temperatures encountered. Fabrication difficulties were encountered in the manufacture of each of the panels. In contrast to uncooled structures which may function satisfactorily with less than perfect joints, the need for leak tight, unblocked coolant passages for cooled structures demands perfection in the fabrication process. Cleanliness is critical both in the fabrication process where foreign material or oxidation may produce substandard joints, and in operation where foreign material may block small coolant passages with potentially disastrous results." Kelly and Blosser [64] include in their Lessons Learned section: "Taken collectively the studies emphasize the need for testing through the entire anticipated operating range to uncover the 'hidden flaws' which may occur in design or manufacturing." Note again the importance of the information needed from the various areas of the Knowledge Management Domain of Fig. 1.

\subsection{Load-carrying structures}

For rocket-powered space-launch systems, Stanley and Piland [47] recommend: "Aluminum-lithium alloys have the potential to reduce the weight of launch vehicle structures $10-15 \%$ below conventional aluminum; 


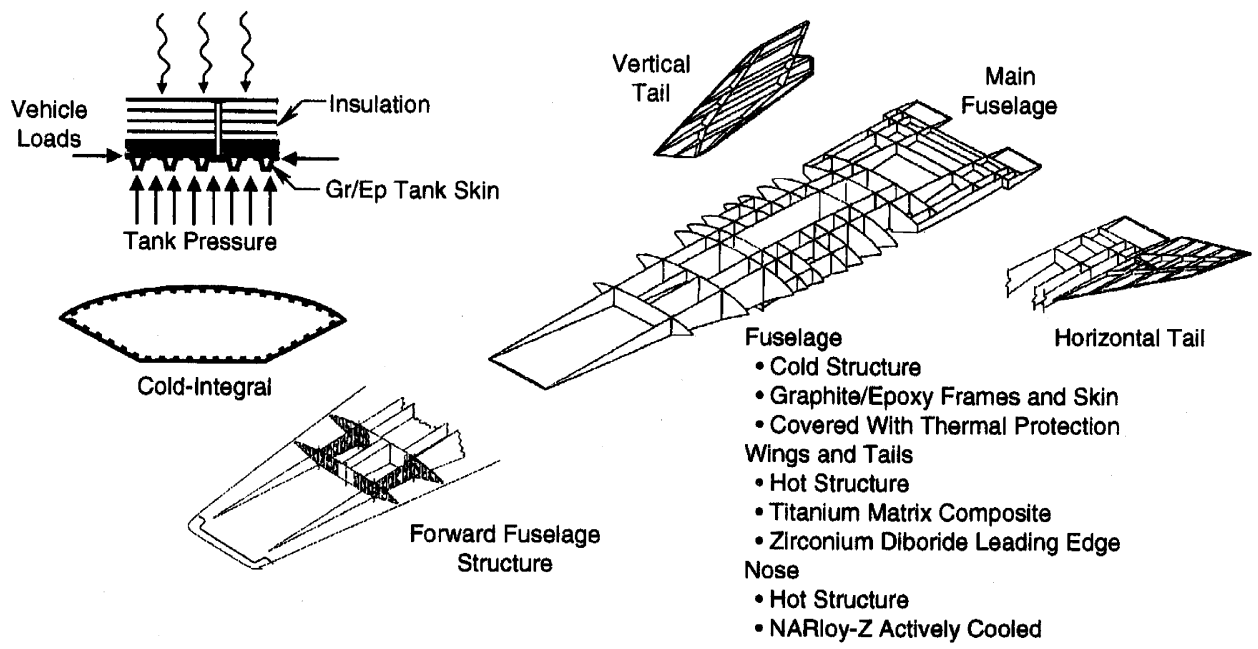

Fig. 17. Mach 10 Dual-Role Vehicle Structure and Materials Ref. [67].

whereas, graphite composites offer the potential for $15-40 \%$ reductions, depending on the application. Graphite/epoxy $(\mathrm{Gr} / \mathrm{Ep})$ is the most technically mature of the candidate composite materials and has relatively attractive material costs; however, its maximum temperature capability is rather low $(390-450 \mathrm{~K})$. Higher temperature $(500-590 \mathrm{~K})$ graphite composites, such as graphite/polyimides and graphite/bismaelimides, can reduce the insulation requirements of future SSV thermal protection systems; however, they require a higher degree of technology investment than graphite/ epoxy materials."

This philosophy carries over into the design strategies for hypersonic cruisers powered by air-breathing propulsion systems. As recommended by Orton and Scuderi [67]: "The Mach 10 dual-role vehicle's airframe is a cold, integral structure design in which the cryogenic hydrogen fuel tanks also carry the vehicle's structural loads. Hot structure is used for the horizontal wings and vertical tails. The nose of the vehicle is also made of hot structure and actively cooled with hydrogen fuel. Main features of the structure are provided in Fig. 17. As can be seen, the frames of the vehicle are made of graphite/epoxy and are covered with graphite/ epoxy skins which help form the integral fuel tanks."

"The skins are covered with a thermal protection system. The horizontal wings and vertical tails are made of titanium matrix composite material and have zirconium diboride composite leading edges. The Pratt \& Whitney ram/scramjet is also actively cooled."

\section{A look into the future}

Great strides have been made in fifty-plus years of hypersonic flight. Even with many years of progress in designing, in building, and in flying hypersonic gliding reentry vehicles, the fatal flight of the Columbia in February 2003 underscores the severity of the hypersonic environment. Hypersonic systems are complex, difficult to design, and expensive to build.

Nevertheless, access-to-space remains a mission that requires systems that perform well in a hypersonic environment. Designers are faced with the realization that the STS, or Space Shuttle, is nearing the end of its life as a man-rated, primary system for the transport of large payloads to orbit.

Will the next generation's access-to-space system be powered, at least in part, by an air-breathing propulsion system? If so, the designers of such a system must design and develop "combined cycle vehicles" that integrate different propulsion systems so that the total system is capable of efficient flight over a wide range of hypersonic Mach numbers. Improvements in structures, materials, and manufacturing technology are needed to accommodate the development of light-weight, highstrength materials that can be efficiently manufactured into structures capable of withstanding the hypersonic environment. It is well to recall the comments regarding the HRE program that were presented in Ref. [5]. "HRE was the victim of unusual times. In the beginning the inflated technical optimism of the early 1960s resulted in over-estimation of technology readiness, and failure to examine in depth the difficult problems and high costs of combining an elaborate new flight engine with a complex hypersonic research airplane. Agency approvals were granted too easily with little depth of conviction and no real commitment on the part of highlevel managers. Later, in the economic retrenchment necessitated by the war in Viet Nam, the approvals so readily given were just as readily withdrawn; the X-15 program was terminated, and HRE degenerated to 
a costly wind-tunnel program using partial simulation test models."

The successful development of a multi-cycle access-tospace vehicle will probably require 20 years, or more. If so, an improved, rocket-propelled system, which is composed of a to-be-determined number of stages, is needed to provide efficient and reliable access-to-space for the interim. Studies are regularly conducted on how to reduce costs, while increasing the reliability and reusability of access-to-space systems. Mankins [68] notes: 'Space launch is a classic 'chicken-and-egg' problem. In general, very low recurring costs per pound of payload can be achieved only with high launch rates. However, such high launch rates require sufficient revenue-generating traffic, which, in turn, depends on prior investment in space enterprises. But that investment, whether governmental or commercial, depends on the prior assured availability of reliable, low-cost launch services. The challenge, therefore, is to devise advanced systems that promise launch costs low enough, even at moderate launch rates, to stimulate the kind of significant market growth that would lead to even lower launch costs and prices."

A reduction of $25-50 \%$ in recurring operational costs while improving system reliability and availability can probably be accomplished by knowledge re-use. That is, achieving the desired reduction in cost, while improving safety and reliability by incremental amounts, can be achieved by activities in the upper right-hand quadrant of Fig. 1. To do this, the designers of a new launch system should focus on improving the following attributes [69]:

1. Affordability - relates to launch costs; one measure being the cost per pound of payload to the desired orbit.

2. Availability-relates to the probability that the vehicle will be launched at the scheduled time, within some reasonable tolerance.

3. Capability-relates to the performance; the ability to place the desired payload (size and weight) into the desired orbit, per launch or per period of time.

4. Certifiability - relates to the ability to certify a launch system by type in a fashion similar to an airliner in the commercial aircraft industry; relates to the reliability, predictability, and safety of a launch system.

5. Environmental compatibility-relates to vehicle manufacturing, testing, and launch without having an adverse impact on the environment.

6. Maintainability - relates to the life-cycle costs.

7. Operability - relates to a combination of availability and responsiveness.

8. Predictability - the launch system works as advertised.
9. Reliability — relates to the probability of successfully inserting a given payload into the proper orbit.

Of course, the relative importance of a particular attribute depends on the application, which depends on the customer. These attributes are often called "ilities".

Chase and Tang [70] conclude: "The vehicle design requirements for SSTO vehicles are beyond current technology capabilities, both for rocket as well as airbreathing combined-cycle engine powered vehicles. In the case of rocket-powered vehicles the design space is very small. Rocket engines whose performance is in the 450 specific impulse range are available. Improvements of perhaps $5-10 \mathrm{~s}$ can be obtained by adding a twoposition nozzle to the current SSME. Improvements in engine thrust-to-weight ratio require new generation of materials. A usable propellant fraction has been demonstrated in the range of $0.86-0.88$. These specific impulse and usable propellant fraction combinations have not produced a mission-closed design. New materials, new fuels, improvements in engine thrust to weight, dual fuel, densified fuel (slush hydrogen) combined with a new design concept may in the future produce a mission-closed design for low Earth orbit." By comparison, for a two-stage-to-orbit (TSTO) system, Chase and Tang [70] note: "Currently, a TSTO airbreathing combined-cycle engine or a rocket-powered TSTO RLV represents the lowest risk approach to lower space transportation costs. The nearer the need date for a reusable launch vehicle, the more the rocket-powered vehicle becomes the vehicle of choice. It will take approximately 10-15 years to develop an air breathing combined-cycle engine based on current NASA plans."

In each decade, a new requirement for building a hypersonic vehicle is identified, sparking a resurgence of interest in hypersonics. There is considerable energy spent designing new concepts and developing the technology base required to support them. But accessto-space vehicles do not yet provide routine, low-cost opportunities to the entrepreneur. No global reach aircraft capable of flying at Mach numbers of 10 , and beyond, has been built. X-programs, such as the X-30, the $\mathrm{X}-33$, and the $\mathrm{X}-38$, have failed short of the flight tests that would produce the data, so necessary to advance our understanding of the hypersonic environment and how to design vehicles that would survive in that environment.

\section{Concluding remarks}

The hypersonic environment is harsh and nonforgiving. New programs often uncover the unknown unknowns. Early flights of a new system have often revealed problems of which the designers were unaware. 
Such problems include: the ineffectiveness of the body flap for the Space Shuttle Orbiter, the viscous/inviscid interactions produced by the umbilical fairings that damaged the conical section TPS of the Gemini Capsule, and the shock/shock interaction that damaged the X-15A-2 when it carried the HRE.

Thus, a sustained and visionary effort to generate the required knowledge both through targeted research activities, as well as through prospecting. Such programs should look for traps and surprises, so that designs that are based on the results of tests of coupon-sized specimens do not fail, when full-sized specimens are tested in cycles of the full-mission-load environments. Or else our grand children will write a similar paper in 50 years, proposing technologies that will lower the cost of placing a payload into low-earth orbit to less than $\$ 100$ per pound, adjusted for inflation.

\section{References}

[1] Bertin JJ. Hypersonic aerothermodynamics. Washington, DC: AIAA; 1994.

[2] Tsien HS. Similarity laws of hypersonic flows. J Math Phys 1946;25:247-51.

[3] Walter WC. Project Dyna-Soar: the roots of shuttle-a memoir. IAA Paper 92-0193, 1992.

[4] Houchin RF. The rise and fall of Dyna-Soar: a history of Air Force hypersonic R\&D, 1944-1963. PhD dissertation, Auburn University, 1995.

[5] Houchin RF. In: Hallion R editor. The hypersonic revolution, case studies in the history of hypersonic technology, vol. II: From scramjet to the national aerospace plane. Ohio: Aeronautical Systems Division, WrightPatterson Air Force Base, 1987.

[6] Matsch L, McMasters J. Private Communication.

[7] Matsch L, McMasters J. New World Vistas, US Air Force Scientific Advisory Board, 1995.

[8] Allen HJ, Eggers AJ. A study of the motion and aerodynamic heating of missiles entering the Earth's atmosphere at high supersonic speeds. NACA TN-4047, October 1957.

[9] Hirschel EH. Viscous effects. In: Space course 1991, Aachen, February 1991. p. 12-1-12-35.

[10] Armstrong JG. Flight planning and conduct of the X-15A2 envelope expansion program. Air Force Flight Test Center FTC-TD-69-4, July 1969.

[11] Lees L. Hypersonic flow. Proceedings of the Fifth International Aeronautical Conference, Institute of the Aeronautical Sciences, 1955. p. 241-76.

[12] Lees L. Laminar heat transfer over blunt-nosed bodies at hypersonic flight speeds. Jet Propulsion 1956;26(4): 259-69.

[13] Fay JA, Riddell FR. Theory of stagnation point heat transfer in dissociated air. J Aeronaut Sci 1958;25(2): 73-85, 121 .

[14] Buck ML, Benson BR, Siero TR, Neumann RD In: Scala SM, Harrison AC, Rogers M, editors. Aerodynamic and performance analyses of a superorbital re-entry vehicle.
Dynamics of manned lifting planetary entry. New York: Wiley; 1963.

[15] Martin JJ. Atmospheric re-entry: an introduction to its science and engineering. Englewood Cliffs, NJ: PrenticeHall; 1966.

[16] Sutton K. Air radiation revisited. In: Nelson HF, editor. Thermal design of aeroassisted orbital transfer vehicles. New York: American Institute of Aeronautics and Astronautics; 1985.

[17] Lee DB, Goodrich WD. The aerothermodynamic environment of the Apollo command module during superorbital entry. NASA TN D-6792, April 1972.

[18] Gazley C. Boundary-layer stability and transition in subsonic and supersonic flow. J Aeronaut Sci 1953;20: 19-28.

[19] Low GM. Boundary-layer transition at supersonic speeds. NACA RM E56E10, August 1956.

[20] Van Driest ER, Boison JC. Experiments on boundarylayer transition at supersonic speeds. J Aeronaut Sci 1957; 24:885-99.

[21] Laufer J, Vrebalovich T. Stability and transition of a supersonic laminar boundary layer on an insulated flat plate. J Fluid Mech 1960;9:257-99.

[22] Van Driest ER. Calculation of the stability of the laminar boundary layer in a compressible fluid on a flat plate with heat transfer. J Aeronaut Sci 1952;19:801-12.

[23] Lees L. The stability of the laminar boundary layer in a compressible fluid. NACA Report 876, 1947.

[24] Schneider SP. Effects of high-speed tunnel noise on laminar-turbulent transition. J Spacecr Rockets 2001; 38(3):323-33.

[25] Schneider SP, Skoch C, Rufer S, Matsumura S, Swanson E. Transition research in the Boeing/AFOSR Mach-6 quiet tunnel. AIAA Paper 2002-0302, January 2002.

[26] Owen FK, Horstman CC, Stainback PC, Wagner RD. Comparison of wind tunnel transition and freestream disturbances measurements. AIAA J 1975;13(3):266-9.

[27] Beckwith IE, Bertram MH. A survey of NASA Langley studies on high-speed transition and the quiet tunnel. NASA TM X-2566, July 1972.

[28] Reshotko E. Boundary-layer stability and transition. Annu Rev Fluid Mech 1976;8:311-49.

[29] Schneider SP. Flight data for boundary-layer transition at hypersonic and supersonic speeds. J Spacecraft Rockets 1999;36(1):8-20.

[30] Bushnell DM. Hypersonic flight experimentation - status and shortfalls. In: Symposium on future technology in service to the alliance, AGARD CP-6000, 1997.

[31] Bouslog SA, An MY, Hartmann LN, Derry SM. Review of boundary layer transition flight data on the Space Shuttle orbiter. AIAA Paper 91-0741, January 1991.

[32] Reda DC. Correlation of nosetip boundary-layer transition data measured in ballistics-range experiments. AIAA J 1981;19(3):329-39.

[33] Reda DC. Review and synthesis of roughness-dominated transition correlations for reentry applications. J Spacecr Rockets 2002;39(2):1-167.

[34] Goodrich WD, Derry SM, Bertin JJ. Shuttle Orbiter boundary-layer transition at flight and wind tunnel conditions. In: Shuttle performance: lessons learned, NASA CP-2283, 1983. 
[35] Edney BE. Anomalous heat transfer and pressure distributions on blunt bodies at hypersonic speeds in the presence of an impinging shock. Flygtekniska Foersoeksanstalten (FFA) Rept. 115, 1968.

[36] Edney BE. Effects of shock impingement on the heat transfer around blunt bodies. AIAA J 1968;6(1):15-21.

[37] Keyes JW, Hains FD. Analytical and experimental studies of shock interference heating in hypersonic flows. NASA TN D-7139, May 1973.

[38] Bertin JJ, Graumann BW, Goodrich WD. Aerothermodynamic aspects of shock-interference patterns for Shuttle during entry. J Spacecr Rockets 1973;10(9):545-6.

[39] Bertin JJ, Graumann BW, Goodrich WD. High velocity and real-gas effects on weak two-dimensional shockinteraction patterns. J Spacecr Rockets 1975;12(3):155-61.

[40] Bertin JJ, Mosso SJ, Barnette DW, Goodrich WD. Engineering flow fields and heating rates for highly swept wing leading edges. J Spacecraft Rockets 1976;13(9):540-6.

[41] Thomas JL, Dwoyer DL, Kumar A. Computational fluid dynamics for hypersonic airbreathing aircraft. In: Desideri JA, Glowinski R, Periaux J, editors. Hypersonic flows for reentry problems, vol. I. Berlin: Springer, 1991.

[42] Gaitonde D, Shang, JS. A numerical study of shock-onshock viscous hypersonic flow past blunt bodies. AIAA Paper 90-1491, June 1990.

[43] Stollery JL. Some aspects of shock-wave boundary-layer interactions relevant to intake flows. In: Aerodynamics of hypersonic lifting vehicles, AGARD CP-428, 1987.

[44] Billig FS. Propulsion systems from takeoff to high-speed flight. In: Murthy SNB, Curran ET, editors. High-speed flight propulsion systems. Washington, DC: American Institute of Aeronautics and Astronautics; 1991.

[45] Humble RW, Henry GN, Larson WJ. Space Propulsion analysis and design. New York: McGraw-Hill Space Technology Series; 1995.

[46] Putnam S. Personal communication, June 2003.

[47] Stanley DO, Piland WM. Technology requirements for affordable single stage rocket launch vehicles. Space Technol 1994;14(5):319-30.

[48] Orton GF, Scuderi LF, Sanger PW, Artus J, Harsha PT, Laruelle G, Shkadov LH. Airbreathing hypersonic aircraft and transatmospheric vehicles. In: Noor AK, Venneri SL, editors. Future aeronautical and space systems. Reston, VA: American Institute of Aeronautics and Astronautics; 1997.

[49] Hunt JL, Laruelle G, Wagner A. Systems challenges for hypersonic vehicles. In: Future aerospace technology in the service of the alliance, AGARD CP-6000, 1997.

[50] Hoegenauer E, Loelle D. SAENGER, the German aerospace program. AIAA Paper 89-5007, July 1989.

[51] Gord PR, Langan KJ, Stringer ME. Advanced launch vehicle configurations and performance trades. In: Space vehicle flight mechanics, AGARD CP-489, 1990.

[52] Blankson IM. Air-breathing hypersonic waveriders: a survey of research needs. In: Anderson JD, Lewis MJ, Corda J, Blankson IM, editors. Proceedings of the First International Waverider Symposium, University of Maryland, College Park, MD, October 1990.
[53] Curran ET, Heiser WH, Pratt DT. Fluid phenomena in scramjet combustion systems. Annu Rev Fluid Mech 1996;28:323-60.

[54] Foster RW, Escher WJD, Robinson JW. Studies of an extensively axisymmetric rocket based combined cycle (RBCC) engine powered SSTO vehicle. AIAA Paper 89-2294, July 1989.

[55] Curran ET. The potential and practicality of high speed combined cycle engines. In: AGARD CP-79, 1990.

[56] Gregory TJ, Petersen RH, Wyss JA. Performance tradeoffs and research problems for hypersonic transports. J Aircr 1965;2(4):266-71.

[57] Bogar TJ, Alberico JF, Johnson DB, Espinos, AM, Lockwood MK. Dual-fuel lifting body configuration development. AIAA Paper 96-4592, November 1996.

[58] Freeman D, Wurster K. The role of flight tests in hypersonic vehicle design. Proceedings of the Second Joint Europe/US Short Course in Hypersonics, US Air Force Academy, CO, January 1989.

[59] McClinton CR, Voland RT, Holland SD, Engelund WC, White J, Pahle JW. Wind-tunnel testing, flight scaling and flight validation with Hyper-X. AIAA Paper 98-2866, June 1998.

[60] Engelund WC. Hyper-X aerodynamics: the X-43A airframe-integrated scramjet propulsion flight-test experiments. J Spacecr Rockets 2001;38(6):801-2.

[61] Schweikart L. The hypersonic revolution, case studies in the history of hypersonic technology, vol. III: the quest for the orbital jet the national aero-space plane program (1983-1995), Air force History and Museums Program, 1998.

[62] Schweikart L. Defense science board task force propulsion sub-panel review of tech mat. March 1987, WPAFB History Office.

[63] Curry DM. Thermal protection systems manned spacecraft flight experience. In: Current technology for thermal protection systems, NASA CP 3157, 1992.

[64] Kelly HN, Blosser ML. Active cooling from the sixties to NASP. In: Current technology for thermal protection systems, NASA CP 3157, 1992.

[65] Rasky DJ. Advanced ceramic matrix composites for TPS. In: Current technology for thermal protection systems, NASA Conference Publication CP 3157, 1992.

[66] Goldstein H. Reusable thermal protection system development - a prospective. In: Current technology for thermal protection systems, NASA Conference Publication CP 3157, 1992.

[67] Orton GF, Scuderi LF. A hypersonic cruiser concept for the 21st century. SAE Paper 985525, September 1998.

[68] Mankins JC. Lower costs for highly reusable space vehicles. Aerosp Am 1998;36(3):36-42.

[69] Bertin JJ, Johnson SW. Access to space-systems and technologies to support it. J Aerosp Eng 1997;10(2): 53-9.

[70] Chase R, Tang M. The quest for single stage earth-toorbit: TAV, NASP, DC-X, and X-33 accomplishments, deficiencies, and why they did not fly. AIAA Paper 20025143, October 2002. 